\title{
Functional interplay between long non-coding RNAs and the Wnt signaling cascade in osteosarcoma
}

\author{
Jieyu He ${ }^{3 \dagger}$, Lin Ling ${ }^{1 \dagger}$, Zhongyue Liu', Xiaolei Ren ${ }^{1,2}$, Lu Wan ${ }^{1}$, Chao Tu ${ }^{1,2^{*}}$ (ID and Zhihong $\mathrm{Li}^{1,2^{*}}$ (D)
}

\begin{abstract}
Osteosarcoma is a common and highly malignant bone tumor among children, adolescents and young adults. However, the underlying molecular mechanisms remain largely unexplored. LncRNAs are transcripts with no or limited protein-coding capacity in human genomes, and have been demonstrated to play crucial functions in initiation, progression, therapeutic resistance, recurrence and metastasis of tumor. Considerable studies revealed a dysregulated IncRNA expression pattern in osteosarcoma, which may act as oncogenes or suppressors to regulate osteosarcoma progression. Wnt signaling pathway is an important cascade in tumorigenesis by modulation of pleiotropic biological functions including cell proliferation, apoptosis, differentiation, stemness, genetic stability and chemoresistance. Hyperactivation or deficiency of key effectors in Wnt cascade is a common event in many osteosarcoma patients. Recently, increasing evidences have suggested that IncRNAs could interplay with component of Wnt pathway, and thereby contribute to osteosarcoma onset, progression and dissemination. In this review, we briefly summarize Wnt signaling-related IncRNAs in osteosarcoma progression, aiming to gain insights into their underlying crosstalk as well as clinical application in osteosarcoma therapeutic modalities.
\end{abstract}

Keywords: LncRNA, Wnt, $\beta$-catenin, Osteosarcoma, Drug resistance, Stemness

\section{Introduction}

Osteosarcoma is one of the most prevalent bone malignancies and account for an inordinate amount of tumorrelated deaths in pediatric and adolescents patients $[1$, 2]. Currently, the standardized approaches are a combination of surgical resection and neoadjuvant/adjuvant chemotherapy [3]. Due to its high aggressiveness and risk of metastatic progression and recurrence after therapy, the prognosis of osteosarcoma is still dismal. Despite several advancements have been achieved in the multimodal treatment, the survival rate for osteosarcoma patients

\footnotetext{
*Correspondence: tuchao@csu.edu.cn; lizhihong@csu.edu.cn

${ }^{\dagger}$ Jieyu He and Lin Ling contributed equally in this work

${ }^{1}$ Department of Orthopedics, The Second Xiangya Hospital, Central

South University, No 139 Middle Renmin Road, Changsha 410011, Hunan, China

Full list of author information is available at the end of the article
}

has reached a plateau. Currently, it is estimated that the 5 -year survival rate is around $75 \%$ for localized osteosarcoma and only $30 \%$ in metastatic patients $[4,5]$. Besides, the regulatory network in osteosarcoma is still obscure, and thus no targeted therapy could be implemented, posing a significant challenge to current modalities [6]. Therefore, it is a substantial need to explore the underlying molecular biology and pathogenesis in osteosarcoma progression and to develop corresponding novel therapies to improve the prognosis of patients $[7,8]$.

Long non-coding RNAs (LncRNAs) refer to a cluster of non-coding RNAs (ncRNAs) that longer than 200 nucleotides, with no or limited protein-coding ability [9]. Due to rapid development of next-generation sequencing, accumulating lncRNA transcripts have been unveiled and annotated in recent years $[10,11]$. Aberrant expression and dysregulation of lncRNAs has been implicated in the 
pathophysiology of a broad spectrum of human diseases, ranging from aging [12-14], neurodegenerative diseases [15], osteoarthritis [16], and cancers [17-20]. LncRNAs could participate in diverse biological processes, including cell survival, apoptosis, differentiation, DNA damage repair, and inflammation [21]. Mechanistically, the most commonly reported feature of lncRNAs is to act as a competing endogenous RNA (ceRNA) to regulate miRNA expression and thus to target downstream genes [22]. Besides, lncRNAs could also interact with macromolecules such as DNA, RNA and proteins to modulate expression of target genes at transcriptional, posttranscriptional and translational level, providing for multiple layers of control, as shown in Fig. 1 [21, 23]. Generally, the function of IncRNAs is location-specific [24]. For instance, the nucleus lncRNAs are usually engaged in chromatin remodeling, mRNA splicing, epigenetic regulation and phase separation [25], while those lncRNA in cytoplasm are involved in translational and post-translational modifications [23, 26].

Moreover, lncRNAs are reported to interplay with several important pathways in tumorigenesis, including Hippo [27], Notch [28], Hedgehog [29], PI3K/Akt [30], JAK/STAT [31] and Wnt [32], to exert a variety of effects in cellular processes. Of them, Wnt cascade is highly complex, while its function and cross-interplay with others remain largely unknown. Given its central and pleiotropic effects in cancer, including proliferation, cell fate specification and differentiation, and mitogenic stimulation, Wnt signaling has attracted much attention in recent decades. In osteosarcoma, IncRNAs play a regulatory role in the occurrence and development of osteosarcoma. Various lncRNAs exert promoting or inhibitory effects by targeting OS cell proliferation, invasion and migration via these above-mentioned oncogenic pathways. In addition, IncRNAs act in the ceRNA system to impact the lncRNAs-miRNAs interaction. More detailed mechanisms are involved in two recently-published reviews by Zhang et al. and Han et al. $[1,33]$. There are several papers concerning roles of lncRNAs or Wnt/ $\beta$ catenin pathway in osteosarcoma or crosstalk between lncRNAs and Wnt pathway with a few depictions of the intersection among these three [1, 6, 34]. However, the complex crosstalk and regulatory loop between lncRNAs and Wnt signaling pathway in osteosarcoma is still elusive, and have not been reviewed in details. In the context of this review, we summarized the most recent knowledge regarding the functional role of lncRNAs associated with Wnt signaling pathway, aiming to provide novel insights into understanding osteosarcoma pathogenesis and reveal a potential clinical application of Wnt signaling pathway-related lncRNAs in osteosarcoma.

\section{Wnt signaling pathway in tumorigenesis of osteosarcoma}

Wnt signaling was firstly discovered in 1982, and is a highly evolutionarily conserved regulatory system [35, 36]. It has been identified to control multiple biological functions, including but limited to cell fate determination, differentiation, cell polarity, stem cell renewal, and mitogenic stimulation during embryonic development and tissue homeostasis [37, 38].

\section{Canonical and non-canonical Wnt signaling pathways}

The Wnt family consists of canonical and non-canonical pathways, which is $\beta$-catenin-dependent and $\beta$-cateninindependent, respectively [39]. Typically, the canonical pathway is best-characterized and its functions are driven by transcriptional co-activator $\beta$-catenin [40], as shown in details in Fig. 2. The Wnt proteins (secreted glycoproteins) couple with several receptors, such as Frizzleds (FZDs), low-density lipoprotein receptorrelated proteins (LRPs) at the plasma membrane, to activate downstream pathways [40]. In the absence of
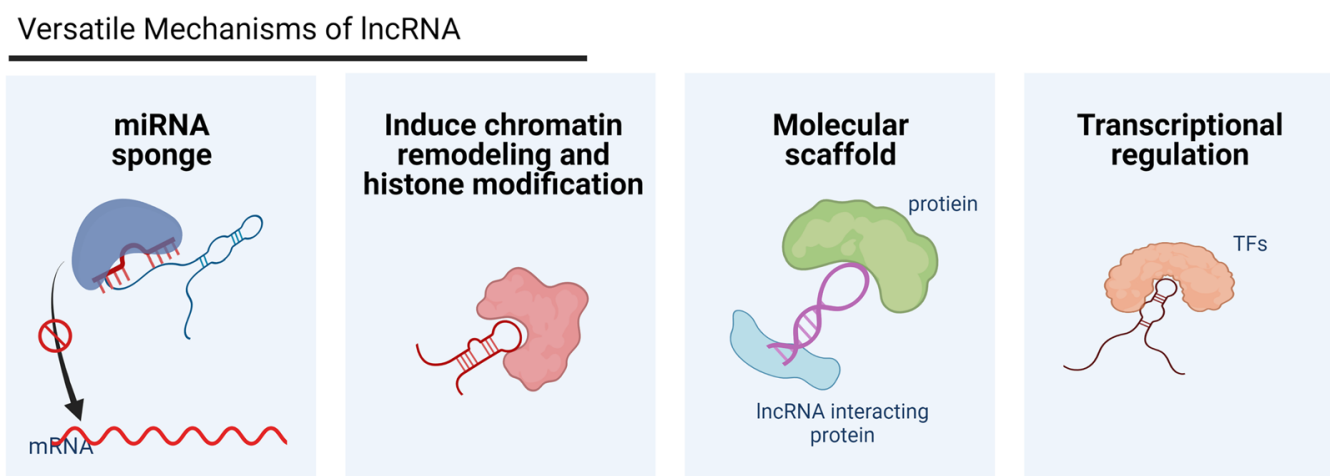

Fig. 1 The schematic drawing shows partial regulatory mechanisms of action of IncRNA. Figure created with BioRender.com 


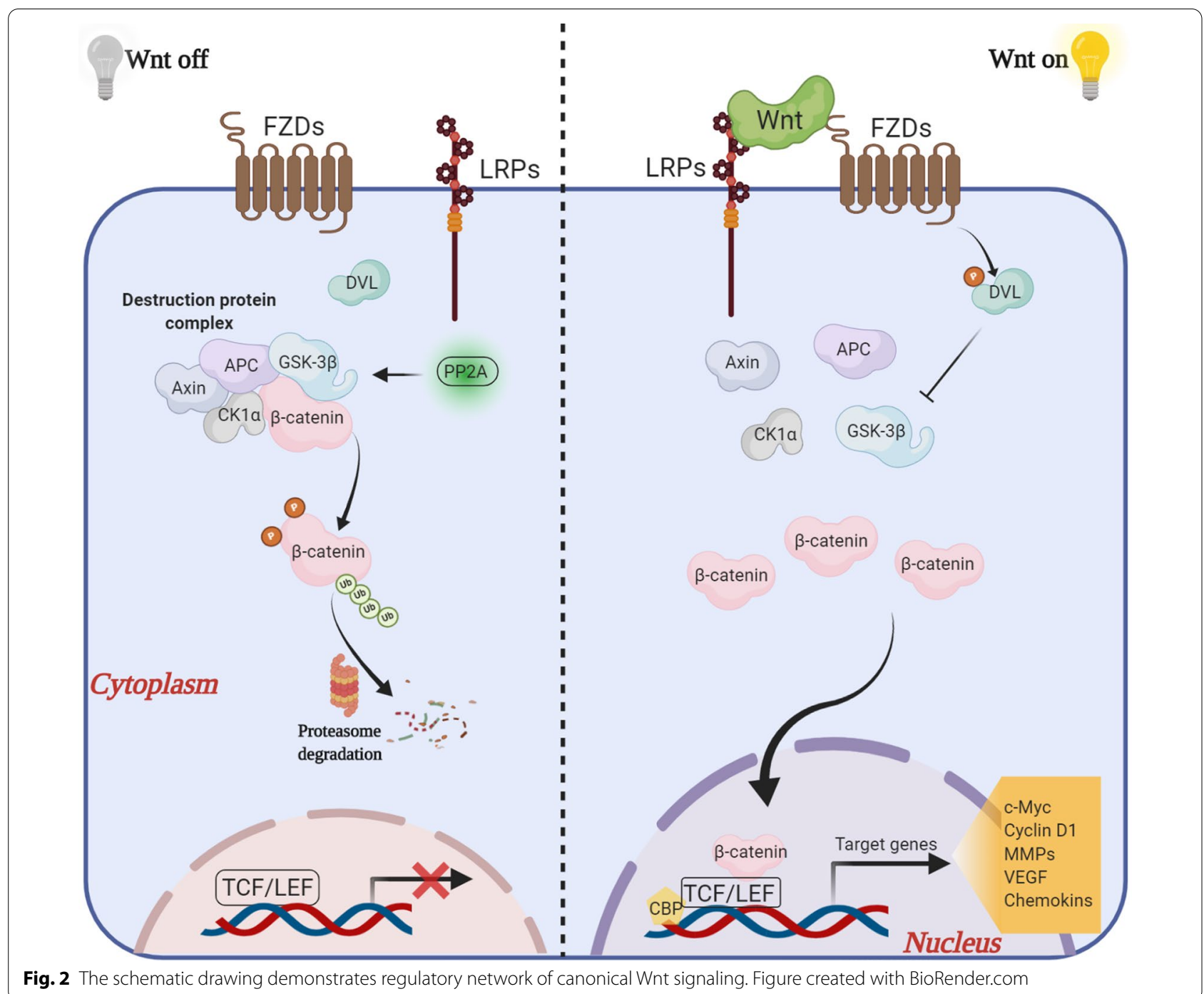

extracellular Wnt ("Wnt off"), $\beta$-catenin is sequestrated, phosphorylated and subsequently degraded mediated by proteasome and tightly controlled by a "destruction protein complex" comprising adenomatous polyposis coli (APC), casein kinase $1 \alpha(C K 1 \alpha)$, glycogen synthase kinase $3 \beta$ (GSK-3 $\beta$ ), protein phosphatase $2 \mathrm{~A}$ (PP2A) and Axin that binds to $\beta$-catenin for destruction [41]. In contrast, upon stimulation by Wnt ("Wnt on"), the cytoplasmic dephosphorylated $\beta$-catenin is maintained, accumulated and translocated into nucleus, which thereby interacts with transcriptional factors $\mathrm{T}$ cell factor (TCF)/ lymphoid enhance factor (LEF) families, and CREB-binding protein (CBP) to initiate the expression of a large set of important developmental genes, such as c-Myc, Cyclin D1, matrix metalloproteinases (MMPs), vascular endothelial growth factors (VEGFs) and chemokines [42, 43].
Besides, the non-canonical branch functions in a $\beta$-catenin-independent manner. It can be further classified into two pathways, namely the Wnt/planar cell polarity (PCP) and the Wnt/Ca ${ }^{2+}$ pathway, which coexist and share certain overlapping components with the canonical one [44]. The Wnt/PCP pathway is also known as the Wnt/JNK pathway. Upon triggering, it cooperates with receptor tyrosine kinase-like orphan receptor 2 (ROR2)/ receptor-like tyrosine kinase (RYK) and activates small GTPases to control cell polarity, cellular cytoskeletal arrangements, adhesion and migration [35, 41, 44]. The Wnt $/ \mathrm{Ca}^{2+}$ pathway activates dishevelled (DVL) and phospholipase C (PLC), causing the release of intracellular $\mathrm{Ca}^{2+}$ ions, which in turn activates protein kinase $\mathrm{C}$ (PKC), phosphatase calcineurin and calcium calmodulin mediated kinase II (CaMKII) that drive transcription of nuclear factor of activated T cells (NFAT)/AP1 gene [35]. 


\section{Wnt signaling in osteosarcoma}

In recent years, the profound implication of Wnt cascade in human cancer development has been well established [37]. Dysregulation in Wnt signaling pathway predisposes patients to multiple cancers. It has been reported that nearly $80 \%$ of the colorectal cancer patients harboring mutations in APC and $\beta$-catenin genes [44]. The Wnt receptor FZD6 was reported to be frequently amplified in breast cancer, with a particular increased incidence in triple-negative breast cancer [45]. Meanwhile, genomic analysis also revealed $46 \%$ of gastric cancer harboring deregulation of Wnt cascade [46].

In addition, deficiency or hyperactivation of Wnt may be responsible for the cancer aggressive behavior or therapy response. In glioblastoma, the Wnt signal is closely correlated with sensitivity to chemo- and radio-therapy $[47,48]$. Another study showed that the Wnt co-receptor ROR1 is expressed in chronic lymphocytic leukemia cells, allowing for targeting these cells with specific monoclonal antibody (cirmtuzumab) [49, 50]. Besides, Wnt pathway could participate in angiogenesis $[39,43]$ and immune-surveillance, which are key events in tumor cell dissemination and metastasis [6]. It is well-known that $\mathrm{Wnt} / \beta$-catenin pathway plays a crucial role in bone tumor microenvironment. Besides the implication of the canonical $\mathrm{Wnt} / \beta$-catenin signaling in angiogenesis [51-54] and immune evasion [55-57], it balances bone remodeling by favoring bone formation but repressing bone resorption [54, 58, 59]. Hyper-activation of Wnt would disrupt this balance in favor of osteosarcoma development and metastasis.

In similar, alteration of the constitutive components of Wnt cascade is also considered as one of the major molecular mechanisms in osteosarcoma initiation and progression [60]. These alterations comprise mutations, amplifications, deletion, promoter hypermethylations, and changes in subcellular localization [61]. A variety of Wnt components, ligands, receptors/co-receptors, and antagonists are dysregulated in osteosarcoma, implying an prominent role of Wnt cascade in tumorigenicity and metastatic dissemination [62]. For example, expression of $\beta$-catenin and its nuclear effector-LEF1 are found both elevated in osteosarcoma tissues [63], and osteosarcoma cells than that in corresponding control $[64,65]$, respectively. LRP5 was frequently expressed in osteosarcoma, and correlated significantly with the chondroblastic subtype of osteosarcoma and metastasis [66-68]. Likewise, another in vivo study also found that dominant negative LRP5 impeded the osteosarcoma tumorigenic potential and metastasis [69]. Meanwhile, secreted Fzdrelated protein 2 (sFRP2) was highly expressed in osteosarcoma patients and inversely correlated with survival. sFRP2 overexpression could induce angiogenesis and drive osteoblast precursors into osteosarcoma phenotype $[39,70]$, while knockdown of sFRP2 impaired its metastatic and invasive behavior [71]. Conversely, inactivation of Wnt inhibitory factor 1 (Wif-1) has been closely correlated with radiation-induced osteosarcoma [72]. Overexpression of another Wnt antagonist, Dickkopf-3 (DKK-3), also retarded tumor growth and pulmonary metastasis in xenograft model [73]. Taken together, these findings highlight the diverse role of Wnt signaling in osteosarcoma.

\section{Regulatory network of IncRNAs and Wnt signaling pathway in osteosarcoma \\ Wnt-related LncRNAs signaling in cell proliferation of osteosarcoma}

Sustained and uncontrolled cell proliferation is an important defining hallmark of carcinogenesis [74]. The relationship between Wnt and osteosarcoma cell proliferation is already well evident [72]. Recently, enormous studies have clarified the involvement of Wnt-related lncRNAs in controlling cell proliferation of osteosarcoma as well.

By analyzing the lncRNA expression pattern in different gene expression omnibus (GEO) datasets, Yao $\mathrm{Q}$ et al. observed that LINC01128 was upregulated in osteosarcoma and negatively correlated with overall survival. In vitro and in vivo study both confirmed that LINC01128 facilitated cell proliferation. Mechanistic exploration revealed that LINC01128 regulated MMP2 through sponging miR-299-3p and activation of Wnt/ $\mathrm{B}$ catenin signaling pathway in osteosarcoma [75].

Lymphoid enhancer-binding factor 1 antisense RNA 1 (LEF1-AS1) was firstly identified to be remarkably correlated with overall and recurrence-free survival of colorectal cancer patients via RNA-seq and microarray data from The Cancer Genome Atlas (TCGA) and GEO [76]. One investigation showed that LEF1-AS1 is upregulated in osteosarcoma with capability to enhance cell proliferation and to stimulate Wnt pathway by sponging heterogeneous nuclear ribonucleoprotein L (HNRNPL) to stabilize mRNA of LEF1. Moreover, the effect of LEF1AS1 deletion could be partially rescued by LEF1 overexpression, which further confirmed a regulatory loop of LEF1-AS1/HNRNPL/LEF1-AS1 in osteosarcoma [64].

Similarly, another recent study showed that small nucleolar RNA host gene 10 (SNHG10) was markedly overexpressed in osteosarcoma compared with adjacent healthy counterparts by quantitative real time polymerase chain reaction (qRT-PCR) and fluorescence in situ hybridization (FISH) analysis [77]. Consistently, higher expression level of SNHG10 is also observed in osteosarcoma cell lines, including MG-63, SW-1353, U-2OS, Sasos-2, HOS, and 143B, when compared with 
osteoblastic cell line hFOB1.19. Colony formation and CCK-8 assay showed that SNHG10 silencing attenuated osteosarcoma cell proliferation in vitro. Moreover, SNHG10 promoted osteosarcoma tumorigenesis in xenograft tumor model. Luciferase reporter assay and RIP further revealed that SNHG10 acted as ceRNA to sponge miR-182-5p and increase expression of FZD3. Accordingly, the Wnt cascade was stimulated, leading to in-nuclear accumulation of $\beta$-catenin and increased expression of target genes including Cyclin D1, cluster of differentiation 44 (CD44), TCF-1 and Axin-2 [77].

\section{Wnt-related LncRNAs in regulation of cellular apoptosis}

Wnt signaling has been well functionally identified to govern cell apoptotic death in osteosarcoma for years $[78,79]$. The Wnt signaling-related lncRNAs have been shown to exert important roles in regulation of cell apoptosis in recent years.

LncRNA down syndrome cell adhesion molecule antisense RNA 1 (DSCAM-AS1) was originally identified as the most abundant Apo-ER $\alpha$-regulated lncRNA (AERlncRNA) in breast cancer [80]. Subsequent work ascribed an oncogenic role for DSCAM-AS1, with the expression in colorectal cancer associated with metastasis, advanced stage and poor overall survival [81], and in breast cancer linked with tumor progression and tamoxifen resistance [82, 83]. Similarly, DSCAM-AS1 was proven highly expressed in osteosarcoma cell lines. In vitro experiments have shown that DSCAM-AS1 depletion could dramatically enhance cell apoptosis in osteosarcoma and inactivate Wnt signaling pathway [84].

Lin $\mathrm{H}$ and colleagues identified another highly expressed lncRNA lnc-MAP6-1:3 in osteosarcoma. Functional experiments convinced that lnc-MAP6-1:3 could accelerate cell proliferation, colony formation and inhibit cell apoptotic death via regulating Bax/Bcl-2 and Wnt/ $\beta$ catenin pathway [85].

TMPO antisense RNA 1 (TMPO-AS1) has been reported to be overexpressed, whereas miR-199a-5p was downregulated in both osteosarcoma tissues and cell lines. Knockdown of TMPO-AS1 repressed cell proliferation, promoted apoptosis and restrained $\mathrm{Wnt} / \beta$-catenin by directly sponging miR-199a-5p to regulate WNT7B. In addition, the suppression by miR-199-5p inhibitor on osteosarcoma could be rescued by WNT7B knockdown, while this effect could be further abolished by $\mathrm{LiCl}$ treatment (activator of Wnt pathway). Taken together, these studies suggested an essential role of TMPO-AS1/miR199a-5p/WNT7B axis in osteosarcoma tumorigenesis [86].

CAT104 is established as an oncogene in several cancers including gastric cancer [87], leukemia [88], and osteosarcoma [89]. CAT104 was shown to be upregulated in osteosarcoma MG-63 and OS-732 cell lines, and its knockdown could restrain cell proliferation and promote apoptosis. Furthermore, CAT104 was found to regulate miR-381 to target zinc finger E-box-binding homeobox 1 (ZEB1) as well as Wnt/ $\beta$-catenin pathways to exert its oncogenic effects on osteosarcoma cells [89].

\section{LncRNA in regulation of Wnt-dependent metastasis and invasion of osteosarcoma}

Early aggressive metastasis could contribute to rapid progression and unfavorable prognosis of osteosarcoma [90]. There are unequivocal evidences that Wnt cascaderelated lncRNAs play a crucial role in regulating invasion, migration and metastasis of osteosarcoma.

Maternally expressed gene 3 (MEG3) is located on human chromosome 14q32.3, and defined as a tumor suppressor in several human cancers [91], such as nasopharyngeal carcinoma [92], breast cancer [93, 94] and ovarian cancer [95]. A recent study reported that MEG3 was aberrantly expressed in osteosarcoma. Forced expression of MEG3 hindered osteosarcoma cell proliferation and migration in vitro, and retarded tumor growth in vivo. Further assay showed that MEG3 negatively regulated miR-184 and downstream effector of Wnt signaling pathway, such as $\beta$-catenin, TCF4 and c-MYC. Moreover, the inhibitory effect of MEG3 could be reversed by miR184 mimic, suggesting a cooperative regulation of MEG3 and miR-184 in osteosarcoma [96].

Another study showed that urothelial carcinoma associated 1 (UCA1) could enhance cell viability, migration and invasion [97]. Expression level of chemokine receptor- C-X-C motif chemokine receptor 4 (CXCR4) has been well-documented to be strongly associated with osteosarcoma invasion and metastasis [98, 99]. Meanwhile, miR-301a was also shown to have a cancerous function in several human cancers including osteosarcoma [100]. Its expression is correlated with cell migration and doxorubicin resistance in osteosarcoma cell lines [101, 102]. Of note, the expression of UCA1 expression was positively related with CXCR4 and miR-301a, and UCA1 could upregulate miR-301a and subsequently increase CXCR4 expression. Moreover, the inhibitory effect of UCA1 knockdown in osteosarcoma cells could be blocked by overexpression of miR-301a, but reversed by CXCR4 inhibition. Interestingly, UCA1 could activate $\mathrm{Wnt} / \beta$-catenin signaling pathway and nuclear factor kappa-B (NF- $\mathrm{kB}$ ) via regulation of miR-301a/CXCR4 axis [97].

Tian $\mathrm{Z}$ et al. demonstrated that $\operatorname{lncSox} 4$ is upregulated in osteosarcoma cell lines and tissues, and boosted cell migration by stabilizing $\beta$-catenin expression. Intriguingly, Wnt agonist CID11210285 abrogated the inhibitory effect on MG-63 cells induced by lncSox4 knockdown, 
while Wnt inhibitor IWP-3 reversed the oncogenic effect on MG-63 caused by $\operatorname{lncSox} 4$ overexpression [103]. Besides, lncRNA CAMK2D-associated transcript 1 (C2dat1) knockdown mitigated osteosarcoma cell invasion and migration by regulating miR-34a-5p/Sirt1 network and Wnt signaling pathway [104].

Enforced (epithelial-mesenchymal transition) EMT is a process in which epithelial cells are transitioned into mesenchymal phenotype, resulting in promoted invasive capacities and unsatisfactory survival rate of cancer patients [105]. EMT can be characterized by increased mesenchymal markers including N-cadherin, Slug, Twist, Vimentin and Fibronectin, but decreased epithelial markers such as E-cadherin [6]. Gastric carcinoma proliferation enhancing transcript 1 (GHET1) is an upregulated lncRNA in osteosarcoma cell lines in comparison with normal osteoblastic cells. GHET1 knockdown was reported to inhibit osteosarcoma cell migration, invasion and EMT, at least in part via regulation of $\mathrm{Wnt} / \beta$-catenin pathway [106].

LncRNA CRNDE was found highly expressed in both osteosarcoma tissues and cell lines. In line with the clinical finding, in vitro study showed that ablation of CRNDE restrained invasion of osteosarcoma cells, downregulated N-cadherin, vimentin and snail, while upregulated expression of E-cadherin and ZO-1. Mechanistically, CRNDE could enhance GSK-3 $\beta$ phosphorylation to trigger Wnt/ $\beta$-catenin signaling pathway [107].

Taurine upregulated gene 1 (TUG1) was also significantly overexpressed in osteosarcoma tissues. Its expression level was positively correlated with distant metastasis and further indicated poor overall and recurrence-free survival [90]. Further study confirmed that enhancer of zeste homolog 2 (TUG1) regulated cell metastatic dissemination by mediating hypoxia-inducible factor -1alpha (HIF-1 $\alpha$ ) via miR-143-5p [90] or EZH2 via miR-144-3p [108]. In addition, inhibition of TUG1 inactivated $\mathrm{Wnt} / \beta$-catenin pathway, and $\mathrm{LiCl}$ could partly abolish the inhibitory effect on cell migration and EMT process induced by TUG1 knockdown [108]. Consistently, another study by Yang GH et al. [109] showed that miR-425-5p overexpression could inhibit osteosarcoma invasion and migration through directly binding to metastasis-associated lung adenocarcinoma transcript 1 (MALAT1) and TUG1, and blocked their activation of Wnt pathway both in vitro and in vivo [109]. Collectively, inhibition of TUG1 and subsequent inactivation of Wnt may be a promising strategy in treating osteosarcoma.

\section{Wnt-related LncRNAs in regulation of cell cycle}

The cell cycle is coordinated by dynamics of master cyclins and cyclin-dependent kinases (CDKs) complex to regulate the sequence and timing of proliferation events
[110]. Disruption of cell cycle progression is an established hallmark of cancer, which may result in uncontrolled cellular proliferation [111]. Phosphorylation of $\beta$-catenin is able to trigger cyclin production, which links the Wnt signaling to cell cycle regulation $[110,112]$. Given the pivotal role of Wnt/ $\beta$-catenin in osteosarcoma cell cycle modulation, some studies have sought to identify the corresponding associated lncRNAs.

High BE503655 expression has been observed in osteosarcoma tissues compared with controls, which is also inversely closed related to Enneking stage, histological grade and distant metastasis [63]. Meanwhile, BE503655 is also highly expressed in osteosarcoma MG-63 and HOS cell lines. Flow cytometry detection revealed that BE503655 silencing obviously arrested the osteosarcoma cells in G0 and G1 phase, while obstructed S phase entry. Meanwhile, expression of BE503655 was positively associated with $\beta$-catenin. BE503655 knockdown in osteosarcoma HOS cells could downregulate $\beta$-catenin as well as an array of Wnt cascade downstream targets, including c-Myc (a proto-oncogene), Cyclin D and MMP2 [63]. Moreover, the cell cycle arrest effect induced by BE503655 knockdown was blocked by $\beta$-catenin overexpression, thus corroborating BE503655 functions in a Wnt/ $\beta$-catenin dependent manner in osteosarcoma [63].

Located at the chromosomal locus 7p15.2, IncRNA HOXA transcript at the distal tip (HOTTIP) has been found to be frequently abnormally expressed in various cancer types, containing gastric cancer [113, 114], lung adenocarcinoma [115], head and neck squamous cell carcinoma [116], pancreatic cancer [117, 118]. Importantly, HOTTIP was the first IncRNA documented to regulate Wnt expression in osteosarcoma. Li Z et al. [119] showed that HOTTIP was overexpressed in both osteosarcoma tissues and cell lines. In vitro experiments revealed that enhanced HOTTIP expression markedly promoted MG-63 osteosarcoma cells into S phase, while HOTTIP downregulation significantly arrested the cell cycle in G1 phase. Mechanistically, HOTTIP overexpression or knockdown in MG-63 cell caused parallel changes in $\beta$-catenin expression, implying that the $\beta$-catenin was directly regulated by HOTTIP. Moreover, HOTTIP could increase expression of cell cycle-related proteins (Cyclin D1 and CDK4) dependent on Wnt/ $\beta$-catenin pathway [119].

\section{Wnt-related LncRNAs in osteosarcoma stemness}

Cancer stem cells (CSCs), also known as tumor initiating cells (TICs), are a small functional subpopulation of cells that exhibit stem-like gene expression [120, 121]. They are considered to be mainly responsible for maintaining tumor cell vitality through self-renewal and infinite proliferation abilities, especially under hypoxia conditions 
$[21,122]$. Besides, CSCs are more resistant to conventional chemotherapy/radiotherapy and even latest immunotherapy [120], which may contribute toward cancer treatment failure and worsening of patients' prognosis [123, 124].

Wnt signaling has been well documented to maintain stem cells in a pluripotent state [35]. Meanwhile, a growing number of studies confirmed a determinant role of lncRNAs in sustaining stemness of CSCs based on analysis of transcriptome sequencing [120]. In one investigation, Li $\mathrm{F}$ et al. reported that lncRNA HOXA transcript antisense RNA, myeloid-specific 1 (HotairM1) is downregulated in CSCs of colorectal carcinoma and uveal melanoma [125]. Further mechanical assay showed that HotairM1 could recruit EZH2 and suppressor of zeste 12 (SUZ12), and consequently form a reciprocal regulation loop with HOXA1-Nanog to augment the tumor stemness effect [125]. More recently, another study reported that lncRNA LHFPL3-AS1 may inhibit apoptosis and maintain stemness viability of melanoma CSCs by sequestration of miR-181a-5p to upregulate Bcl-2 expression [126].

In osteosarcoma, lncRNAs distal-less homeobox 6 antisense 1 (DLX6-AS1) was highly expressed in osteosarcoma tissue and cell lines [123, 127, 128]. Moreover, its expression was significantly correlated with advanced TNM stage, tumor grade, distant metastasis and poor prognosis [123, 127]. Mechanistically, DLX6-AS1 could function as a ceRNA to interact with miR-129-5p to target delta-like homologue 1 (DLK1), and thus form a reciprocal feedback loop to activate Wnt cascade, thereby promoting stemness of osteosarcoma [123]. Taken together, these studies exemplify that specifically targeting Wnt signaling-associated lncRNAs may help promote CSCs elimination, prevent osteosarcoma recurrence, and thus paving a new pathway in the treatment.

\section{Wnt-related LncRNAs in osteosarcoma drug resistance}

Drug resistance remains a multifaceted obstacle in cancer treatment, which may be attributed to tumor heterogeneity, survival pathway activation, and cytotoxic drug efflux [40]. Osteosarcoma patients often develop drug resistance, which may in turn largely impairs the therapeutic effect of chemotherapy, and eventually leads to tumor recurrence $[124,129]$. It is necessary to undermine the mechanisms in osteosarcoma chemoresistance, and thus to provide innovative strategy for efficacy improvement in chemotherapy.

Deregulated Wnt pathway has been demonstrated to favor resistance to conventional chemotherapy [57]. Recently, emerging studies have also highlighted a pivotal role of Wnt signaling-related lncRNA in regulation of chemotherapy sensitivity [116]. For example,
HNF1A-AS1 level was found to be obviously upregulated in cisplatin-resistant cervical cancer cell line. Exosomes carrying HNF1A antisense RNA 1 (HNF1AAS1) enhanced drug resistance by sponging miR-34b to elevate tuftelin1 (TUFT1) expression [130]. P-glycoprotein ( $\mathrm{P}$-gp/ABCB1), encoding by multidrug resistance 1 (MDR1) gene, is regulated by $\beta$-catenin/TCF/LEF-binding sites [41] and defined as a key mediator in acquired chemoresistance [131]. In breast cancer, overexpression of lncRNA growth arrest-specific 5 (GAS5) could remarkably enhance adriamycin sensitivity, while suppress drug efflux and $A B C B 1$ expression via regulation of miR-221-3p/DKK2 axis and Wnt/ $\beta$-catenin pathway [132].

Platinum-based chemotherapy, mainly cisplatin, has been widely applied to suppress osteosarcoma growth and metastasis [133]. Resistance to cisplatin is often associated with poor prognosis in osteosarcoma patients [134]. Recently, an investigation showed that HOTTIP could regulate the cisplatin sensitivity in osteosarcoma [119]. In vitro assay showed that HOTTIP expression conferred cisplatin resistance through activation of Wnt/ $\beta$-catenin signaling pathway. Upon treatment of Wnt $/ \beta$ catenin inhibitor, the cellular resistance to cisplatin could be reversed. Thus, HOTTIP was proposed to sensitize osteosarcoma cells in cisplatin-based chemotherapy via Wnt pathway, uncovering a novel network in osteosarcoma treatment [119].

\section{Possible involvement of IncRNA in mutation of Wnt signaling}

Mutation-induced activation of Wnt pathway frequently drives tumorigenesis and therapy resistance. The excessive activity of $\mathrm{Wnt} / \beta$-catenin pathway could be achieved via following unwanted mutations. Firstly, inactivation of the $\beta$-catenin destruction complex initiated by inactivating mutations of APC, AXIN1 and AXIN2 or activating mutations in $\beta$-catenin, is postulated to drive WNTindependent growth [135-137]. Secondly, loss of RNF43 and ZNRF3 could sustain an over-abundance status of cell surface WNT receptors, which is assumed to promote WNT-dependent tumor growth [138-140]. There are rare findings regarding such function of lncRNA in cancer research. LncRNA CA7-4 decoys MIR877-3p, the latter of which triggers the reduction of CTNNBIP1 (catenin beta interactin protein 1 ) by interacting with its 3'UTR and the upregulating CTNNB1 [141]. Thus, the CTNNB1-encoded $\beta$-catenin might acquire amplified activity, which lacks direct evidence. Future investigations regarding the role of lncRNA in mutation-driven Wnt signaling alterations in tumorigenesis will benefit therapeutic decisions. 
The clinical significance of IncRNAs involved in Wnt pathway in osteosarcoma

Given the fact that most lncRNAs are tissue- or cancercontext-specific, stable in circulatory form [142], and easy for detection $[143,144]$, it is possible that lncRNAs may serve as ideal diagnostic and prognostic biomarkers, as well as promising therapeutic candidates [27].

Abnormal expression of multiple Wnt-related lncRNAs has been demonstrated to be closely associated with clinicopathological features of osteosarcoma. For instance, FLVCR1 antisense RNA 1 (FLVCR1-AS1) is highly expressed in osteosarcoma than adjacent normal tissue, and its expression is positively associated with tumor size, WHO grade and distant metastasis in osteosarcoma patients. Moreover, patients with FLVCR1-AS1 upregulation have unfavorable survival rate [145], indicating that FLVCR1-AS1 may be viable biomarker in osteosarcoma.

LncRNA small nucleolar RNA host gene 1 (SNHG1), one of dysregulated lncRNAs in multiple cancer, is shown to be also involved in pathology of osteosarcoma. SNHG1 is highly expressed in osteosarcoma and positively correlated with tumor size, TNM stage and lymph node metastasis [146].

LncRNA AWPPH expression was elevated in osteosarcoma tissues compared with paracancerous controls [147]. Overexpression of AWPPH was significantly correlated with advanced tumor stage, tumor size, metastasis, and conferred reduced overall survival rate [148].

Expression of HNF1A-AS1 was significantly increased in osteosarcoma tissues in contrast to adjacent normal tissue. Upregulated HNF1A-AS1 overexpression was significantly associated with advanced clinical stage, distant metastasis [149]. Multivariate Cox proportional hazards analysis suggested that HNF1A-AS1 was an independent risk factor of overall survival in osteosarcoma patients [150]. Moreover, serum HNF1A-AS1 was capable to separate osteosarcoma patients from healthy counterparts with the area under curve (AUC) of 0.849 in receiver operating characteristic (ROC) curve [150].

The expression levels of long stress-induced noncoding transcript 5 (LSINCT5) were upregulated in osteosarcoma tissues and cell lines. High LSINCT5 level was positively correlated with malignant clinicopathological features, including advanced Enneking stage and histological grade, larger tumor size, and distant metastasis [151]. Besides, osteosarcoma patients with high expression of LSINCT5 showed a trend toward decreased overall survival $[151,152]$.

Dai $J$ et al. reported that ITGB2 antisense RNA1 (ITGB2-AS1) was upregulated in osteosarcoma tissues, and were negatively correlated with prognosis of osteosarcoma patients [153]. LncRNA actin filamentassociated protein 1-antisense RNA 1 (AFAP1-AS1) has been validated to be highly expressed in osteosarcoma tissues than that of adjacent tissues [154-156], and was negatively correlated with prognosis of osteosarcoma patients [157]. Collectively, the Wnt-related lncRNAs may be potential predictors for clinical outcomes in osteosarcoma.

\section{Potential of Wnt-related IncRNAs as biomarkers and therapeutic targets in osteosarcoma}

Exosomes are small membranous vesicles, which transport cargoes of protein and genetic materials in biological fluids. Accumulating evidence support lncRNAs are enriched in exosomes from osteosarcoma model [158, 159]. Liquid biopsy has been developed to detect early development, advanced and metastasis of osteosarcoma by profiling circulating tumor DNA (ctDNA) and miRNA, but less focus on either exosomes or lncRNA (Using Liquid Biopsy in the Treatment of Patient with OS). Future tumor data profile trends to include lncRNAs, especially exosomal lncRNAs for diagnostic and prognostic purposes.

Above, we have detailed illustrated functions of various Wnt-related lncRNAs in tumor growth, migration, invasion and drug resistance. Wnt-related lncRNAs, including MEG3, MALAT1, TUG1, HOTTIP, GAS5, CRNDE, UCA1 and LSINCT5 have been detected in secreted exosomes, suggesting exosomal lncRNAs can be developed into convenient and noninvasive biomarkers for diagnosis and prognosis [160-166]. However, to our knowledge, the potential of using exosomal lncRNAs in osteosarcoma samples or within body fluids as a source for biomarkers has not been reported. Besides, large gaps still remain on therapeutic application of lncRNAs in osteosarcoma. Firstly, technical problems, such as extraction of exosomes from different specimens must be solved. Sensitivity and specificity of certain exosomal lncRNA as biomarkers could be clarified once exosomes yields are prepared. Secondly, identification of derivation of certain exosomal lncRNAs is necessary for diagnostic and therapeutic purpose. For example, non-tumor cell, especially stem cells-derived lncRNAs can activate diverse target cell activities in modeling tumor microenvironment. Thirdly, delivering lncRNA modulation systems to target live cells remains challenging. Traditional viral vectors carry with high immunogenicity and toxicity. In converse, non-viral vectors are recognized as an alternative to drastic immune response caused by viral vectors. Exosomes are under development of delivery system. More attractively, nucleic-acid aptamers have 
been demonstrated as another promising target delivery method via specific cell surface receptors, which possessed higher cell-type specific and gene-editing effect [167].

Currently, there are three novel therapeutic strategies focusing on lncRNAs in osteosarcoma, including small interfering RNA (siRNA), an antisense oligonucleotide (ASO)-based strategies and molecular inhibitors, all of which modulate lncRNA expression by gene editing [168]. RNAi is an effective method to reduce the amount or activity of target lncRNA via several mechanisms. One is designing siRNA as complementary sequence to lncRNA in purpose to promote lncRNA binding and subsequent degradation, which is efficient for cytoplasmic lncRNAs since the process of siRNA-lncRNA interaction exists predominantly in the cytoplasm. Another mechanism is to target lncRNA-protein interaction. RNAi molecule could compete with the protein for the binding site or disrupting the binding site of protein when interacting with target lncRNA. Conversely, ASOs strategy shows more advantage over RNAi in terms of targeting both nuclear lncRNAs. ASOs bind to target lncRNA to induce gene silencing [169]. ASOs developed to target MALAT1 have shown promising results in cancer treatment [170]. However, both ASO and RNAi strategies have shortcomings in terms of non-specific targets and transient modulation [171-173]. Several improvements have been made to solve the problem of target specificity. One striking methodology is CRISPR/Cas9. The Cas9 nuclease can guide site-specific DNA cleavage or deletion of lncRNA promoters by an optimized single-guide RNA (sgRNA). It has been applied in cancer research especially as potent lncRNA therapeutics with the development of aptamerliposome-CRISPR/Cas9 chimera. One chimera has been adapted to specifically bind to the prostate membrane antigen on prostate cancer cells [174]. The limitations of the preclinical application of CRISPR/Cas9 are offtarget effects and limited lncRNAs as targets. Another very-recently developed technique is CRISPR/Cas13 system, which adopts cas13 endoribonuclease (also known as $\mathrm{C} 2 \mathrm{c} 2$ ) to manipulate reverse genetic edit on target RNA [175]. This promising approach has demonstrated biological relevance of IncRNAs in cancer therapeutics mechanically, which requires further exploration in osteosarcoma.

\section{Conclusions and future perspectives}

Osteosarcoma is a highly aggressive tumor with propensity for local invasion, relapse as well as distant metastasis [176-179]. A comprehensive understanding of the underlying mechanisms involved in osteosarcoma pathogenesis is urgently needed to advance the new therapies for osteosarcoma patients [72].

The Wnt pathway is a highly conserved and versatile pathway that plays a central role in governing cellular proliferation, apoptosis, stemness, drug resistance, and other crucial hallmarks implicated in pathophysiology of cancer $[180,181]$. In the light of these premises, Wnt signaling cascades are defined as interesting and promising therapeutic targets for osteosarcoma treatment [182]. However, owing to its complex nature, the development of drug targeting Wnt signaling may lead to inevitable side effects, and thus has been considered to be impossible for a long time [35]. In recent years, Wnt-targeting therapeutics in other cancer types are in different phases of pre-clinical or early clinical trials, while those for osteosarcoma are still scarcely observed [6, 41]. Recently, lncRNAs are gaining researchers' attention as an alternative strategy for cancer treatment [22, 183, 184]. The increasing insights into the crosstalk between lncRNAs and Wnt in osteosarcoma may lead to the development of promising pharmacological candidates (Shown in Fig. 3; Table 1). Due to its tissue-, cell- and even time-specific expression context, Wnt-related lncRNAs may provide us with a more refined strategy, and less adverse effects than currently available treatment options in osteosarcoma.

Considering the indispensable and diverse role played by lncRNAs in carcinogenesis, it is not surprising that Wnt-related lncRNAs are extensively involved in osteosarcoma progression. It is worthy of note that the majority of currently studies are focused on the upstream regulatory lncRNAs, while the downstream lncRNA targets of Wnt cascade remains largely unexplored. Hence, future studies are warranted to also elucidate the respective role as downstream lncRNA targets. Besides, other alternative regulatory networks concerning the role of Wnt-related lncRNAs in osteosarcoma, in addition to ceRNA, should be addressed. Moreover, it is of great necessity to further validate the sensitivity and specificity of lncRNAs as biomarkers in clinical settings. Established serum markers, such as alkaline phosphatase (ALP) and lactate dehydrogenase (LDH), have been widely adopted to aid in diagnosing osteosarcoma for decades $[185,186]$, and whether these Wnt-related IncRNAs have more advantages over these markers need to be further verified. Due to the easy accessibility and routine availability, the Wnt signaling-related lncRNAs with excellent diagnostic performance may be promising candidates in near future. A more comprehensive understanding of the role of Wnt signaling-related lncRNAs may eventually rationalize novel, yet unexplored, therapeutic opportunities for individualized treatment in osteosarcoma. 


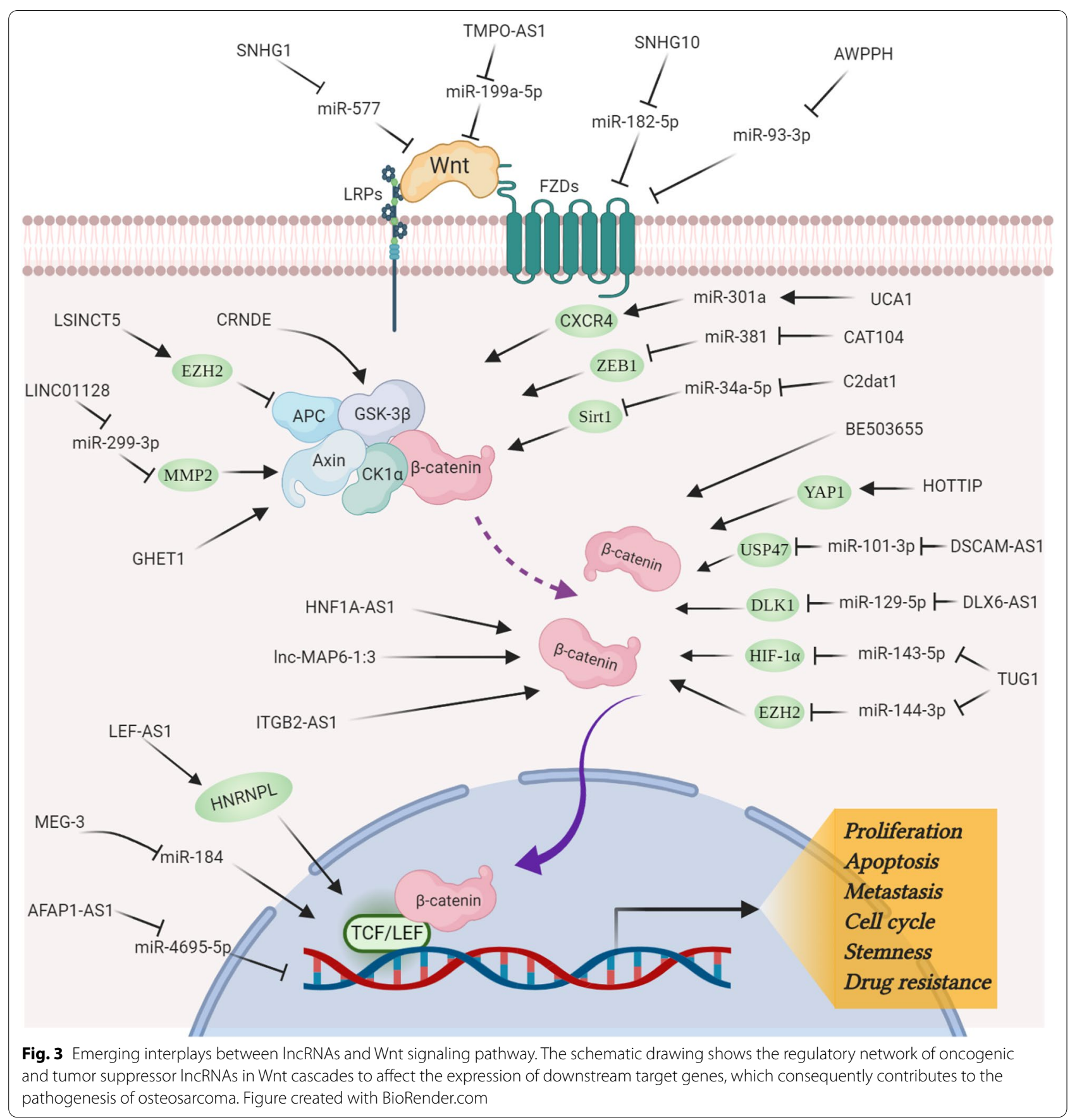


Table 1 Overview of Wnt signaling pathway-related IncRNAs in development of osteosarcoma

\begin{tabular}{|c|c|c|c|c|c|c|c|}
\hline LncRNA & $\begin{array}{l}\text { Expression } \\
\text { pattern }\end{array}$ & $\begin{array}{l}\text { Interaction with } \\
\text { Wnt pathway }\end{array}$ & Target genes & $\begin{array}{l}\text { Associated clinical } \\
\text { values }\end{array}$ & $\begin{array}{l}\text { Cellular } \\
\text { physiological } \\
\text { functions }\end{array}$ & $\begin{array}{l}\text { Regulatory } \\
\text { modality }\end{array}$ & Refs. \\
\hline AFAP1-AS1 & $\uparrow$ & $\begin{array}{l}\text { Activating Wnt/B- } \\
\text { catenin }\end{array}$ & miR-4695-5p/TCF4 & Prognosis & $\begin{array}{l}\text { Proliferation, inva- } \\
\text { sion }\end{array}$ & Transcriptional & [157] \\
\hline AWPPH & $\uparrow$ & $\begin{array}{l}\text { Activating Wnt/B- } \\
\text { catenin }\end{array}$ & miR-93-3p/FZD7 & $\begin{array}{l}\text { Advanced stage, } \\
\text { tumor size, metas- } \\
\text { tasis, survival }\end{array}$ & $\begin{array}{l}\text { Proliferation, migra- } \\
\text { tion, invasion }\end{array}$ & Transcriptional & [148] \\
\hline BE503655 & $\uparrow$ & $\begin{array}{l}\text { Activating Wnt/ } \beta \text { - } \\
\text { catenin }\end{array}$ & - & $\begin{array}{c}\text { Enneking stage, DM, } \\
\text { histological grade }\end{array}$ & $\begin{array}{l}\text { Proliferation, cell } \\
\text { cycle, invasion, } \\
\text { migration }\end{array}$ & Unknown & [63] \\
\hline C2dat1 & $\uparrow$ & $\begin{array}{l}\text { Activating Wnt/B- } \\
\text { catenin, p38/ERK/ } \\
\text { AKT }\end{array}$ & miR-34a-5p/Sirt1 & - & $\begin{array}{l}\text { Cell viability, migra- } \\
\text { tion, invasion, } \\
\text { apoptosis }\end{array}$ & Transcriptional & [104] \\
\hline CAT104 & $\uparrow$ & $\begin{array}{l}\text { Activating Wnt/ } \beta \text { - } \\
\text { catenin, JNK }\end{array}$ & miR-381/ZEB1 & - & $\begin{array}{l}\text { Proliferation, migra- } \\
\text { tion, invasion, } \\
\text { apoptosis }\end{array}$ & Transcriptional & [89] \\
\hline CRNDE & $\uparrow$ & $\begin{array}{l}\text { Activating Wnt/ } \beta \text { - } \\
\text { catenin }\end{array}$ & GSK-3ß & - & $\begin{array}{l}\text { Proliferation, inva- } \\
\text { sion, apoptosis, } \\
\text { cell cycle arrest, } \\
\text { EMT }\end{array}$ & Post-transcriptional & {$[107]$} \\
\hline DLX6-AS1 & $\uparrow$ & Activating Wnt & miR-129-5p/DLK1 & Prognosis & Stemness & Transcriptional & [123] \\
\hline DSCAM-AS1 & $\uparrow$ & $\begin{array}{l}\text { Activating Wnt/ } \beta \text { - } \\
\text { catenin and AKT/ } \\
\text { mTOR }\end{array}$ & miR-101-3p/USP47 & - & $\begin{array}{l}\text { Proliferation, migra- } \\
\text { tion, invasion, } \\
\text { apoptosis }\end{array}$ & Transcriptional & [84] \\
\hline FLVCR1-AS1 & $\uparrow$ & $\begin{array}{l}\text { Activating Wnt/B- } \\
\text { catenin }\end{array}$ & $\begin{array}{l}\text { CTNNB1, SOX4, } \\
\text { CCND1, CCND2, } \\
\text { Myc }\end{array}$ & $\begin{array}{l}\text { Tumor size, WHO } \\
\text { grade, DM, } \\
\text { survival }\end{array}$ & $\begin{array}{l}\text { Proliferation, migra- } \\
\text { tion and invasion }\end{array}$ & Unknown & [145] \\
\hline GHET1 & $\uparrow$ & $\begin{array}{l}\text { Activating Wnt/ } \beta \text { - } \\
\text { catenin }\end{array}$ & - & - & $\begin{array}{l}\text { Proliferation, migra- } \\
\text { tion, invasion, } \\
\text { EMT, apoptosis }\end{array}$ & Unknown & [106] \\
\hline HNF1A-AS1 & $\uparrow$ & $\begin{array}{l}\text { Activating Wnt/ } \beta \text { - } \\
\text { catenin }\end{array}$ & - & $\begin{array}{c}\text { Clinical stage, DM, } \\
\text { overall survival }\end{array}$ & $\begin{array}{l}\text { Proliferation, metas- } \\
\text { tasis }\end{array}$ & Unknown & [149] \\
\hline HOTTIP & $\uparrow$ & $\begin{array}{l}\text { Activating Wnt/ } \beta \text { - } \\
\text { catenin }\end{array}$ & - & Chemoresistance & $\begin{array}{l}\text { Proliferation, cell } \\
\text { cycle, cisplatin } \\
\text { resistance }\end{array}$ & Unknown & [119] \\
\hline ITGB2-AS1 & $\uparrow$ & $\begin{array}{l}\text { Activating Wnt/ß- } \\
\text { catenin }\end{array}$ & - & Prognosis & $\begin{array}{l}\text { Proliferation, apop- } \\
\text { tosis, migration, } \\
\text { invasion }\end{array}$ & Unknown & [153] \\
\hline LEF1-AS1 & $\uparrow$ & Activating Wnt & HNRNPL/LEF1 & - & $\begin{array}{l}\text { Proliferation, migra- } \\
\text { tion, invasion }\end{array}$ & Transcriptional & [64] \\
\hline LINC01128 & $\uparrow$ & $\begin{array}{l}\text { Activating Wnt/B- } \\
\text { catenin }\end{array}$ & miR-299-3p/MMP2 & - & $\begin{array}{l}\text { Proliferation, migra- } \\
\text { tion, and invasion }\end{array}$ & Transcriptional & {$[75]$} \\
\hline Lnc-MAP6-1:3 & $\uparrow$ & $\begin{array}{l}\text { Activating Wnt/B- } \\
\text { catenin and Bax/ } \\
\text { Bcl-2 }\end{array}$ & - & - & $\begin{array}{l}\text { Proliferation, apop- } \\
\text { tosis }\end{array}$ & Post-transcriptional & [85] \\
\hline LncSox4 & $\uparrow$ & Activating $\beta$-catenin & - & - & Viability, migration & Post-transcriptional & [103] \\
\hline LSINCT5 & $\uparrow$ & Activating $\beta$-catenin & $\mathrm{EZH} 2 / \mathrm{APC}$ & Prognosis & $\begin{array}{l}\text { Proliferation, tumor } \\
\text { growth }\end{array}$ & Transcriptional & [152] \\
\hline MEG3 & $\downarrow$ & $\begin{array}{l}\text { Inhibit Wnt/B- } \\
\text { catenin }\end{array}$ & $\begin{array}{l}\text { miR-184/TCF4 and } \\
\text { c-Myc }\end{array}$ & - & $\begin{array}{l}\text { Cell viability, metas- } \\
\text { tasis, apoptosis }\end{array}$ & Transcriptional & [187] \\
\hline TMPO-AS1 & $\uparrow$ & $\begin{array}{l}\text { Activating Wnt/ } \beta \text { - } \\
\text { catenin }\end{array}$ & $\begin{array}{l}\text { miR-199a-5p/ } \\
\text { WNT7B }\end{array}$ & - & $\begin{array}{l}\text { Proliferation, apop- } \\
\text { tosis }\end{array}$ & Transcriptional & [86] \\
\hline SNHG1 & $\uparrow$ & $\begin{array}{l}\text { Activating Wnt/ß- } \\
\text { catenin }\end{array}$ & miR-577/WNT2B & $\begin{array}{l}\text { Tumor size, TNM } \\
\text { stage, LNM }\end{array}$ & $\begin{array}{l}\text { Proliferation, migra- } \\
\text { tion, EMT }\end{array}$ & Transcriptional & [146] \\
\hline SNHG10 & $\uparrow$ & $\begin{array}{l}\text { Activating Wnt/ß- } \\
\text { catenin }\end{array}$ & miR-182-5p/FZD3 & - & $\begin{array}{l}\text { Proliferation, inva- } \\
\text { sion }\end{array}$ & Transcriptional & [77] \\
\hline TUG1 & $\uparrow$ & $\begin{array}{l}\text { Activating Wnt/B- } \\
\text { catenin }\end{array}$ & miR-144-3p/EZH2 & - & $\begin{array}{l}\text { Proliferation, migra- } \\
\text { tion, invasion, } \\
\text { apoptosis }\end{array}$ & Transcriptional & {$[108,109]$} \\
\hline
\end{tabular}


Table 1 (continued)

\begin{tabular}{lllllll}
\hline LncRNA & $\begin{array}{l}\text { Expression } \\
\text { pattern }\end{array}$ & $\begin{array}{l}\text { Interaction with } \\
\text { Wnt pathway }\end{array}$ & Target genes & $\begin{array}{l}\text { Associated clinical } \\
\text { values }\end{array}$ & $\begin{array}{l}\text { Cellular } \\
\text { physiological } \\
\text { functions }\end{array}$ & $\begin{array}{l}\text { Regulatory } \\
\text { modality }\end{array}$ \\
\hline UCA1 & $\uparrow$ & $\begin{array}{l}\text { Activating Wnt/ } \beta- \\
\text { catenin and NF-KB }\end{array}$ & miR-301a/CXCR4 & - & $\begin{array}{l}\text { Cell viability, migra- } \\
\text { tion, invasion, } \\
\text { apoptosis }\end{array}$ & Transcriptional \\
& & & & & {$[97,188]$} \\
\end{tabular}

AFAP1-AS1 actin filament-associated protein 1-antisense RNA 1, APC adenomatous polyposis coli, C2dat1 CAMK2D-associated transcript 1, CXCR4 C-X-C motif chemokine receptor 4, DLK1 delta-like homologue 1, DLX6-AS1 distal-less homeobox 6 antisense 1, DM distant metastasis, DSCAM-AS1 down syndrome cell adhesion molecule antisense RNA 1, EMT epithelial-mesenchymal transition, EZH2 enhancer of zeste homolog 2, FLVCR1-AS1 FLVCR1 antisense RNA 1, FZD3 Frizzled 3, TCF4 transcriptional factors T cell factor4, GHET1 Gastric carcinoma proliferation enhancing transcript 1, GSK-3 $\beta$ glycogen synthase kinase $3 \beta$, HNF1A-AS1 HNF1A-antisense 1, HNRNPL heterogeneous nuclear ribonucleoprotein L, HOTTIP HOXA transcript at the distal tip, ITGB2-AS1 ITGB2 antisense RNA1, LEF1 lymphoid enhance factor 1 , LEF1-AS1 Lymphoid enhancer-binding factor 1 antisense RNA 1, LNM lymph node metastasis, LSINCT5 long stress-induced noncoding transcript 5, MEG3 maternally expressed gene 3, MMP2 maxtrix metalloproteinase 2, Sirt1 Sirtuin 1, SNHG1 small nucleolar RNA host gene 1, SNHG10 small nucleolar RNA host gene 10, TMPO-AS1 TMPO antisense RNA 1, TUG1 taurine upregulated gene 1, UCA1 urothelial carcinoma associated 1, USP47 ubiquitin-specific peptidase 47, ZEB1 zinc finger E-boxbinding homeobox 1, $\uparrow$ :upregulated, $\downarrow$ :downregulated

\section{Abbreviations}

AER-IncRNA: Apo-ERa-regulated IncRNA; AFAP1-AS1: Actin filament-associated protein 1-antisense RNA 1; ALP: Alkaline phosphatase; APC: Adenomatous polyposis coli; ASO: Antisense oligonucleotide; AUC: Area under curve; CaMKII: Calcium calmodulin mediated kinase II; CD44: Cluster of differentiation 44; CDKs: Cyclin-dependent kinases; ceRNAs: Competing endogenous RNA; CtDNA: Circulating tumor DNA; CTNNBIP1: Catenin beta interactin protein 1; DLK1: Delta-like homologue 1; DLX6-AS1: Distal-less homeobox 6 antisense 1; CK1a: Casein kinase 1a; CRNDE: Colorectal neoplasia differentially expressed; CSCs: Cancer stem cells; CXCR4: C-X-C motif chemokine receptor 4; DKK-3: Dickkopf-3; DSCAM-AS1: Down syndrome cell adhesion molecule antisense RNA 1; DVL: Disheveled; EZH2: Enhancer of zeste homolog 2; FISH: Fluorescence in situ hybridization; FLVCR1-AS1: FLVCR1 antisense RNA 1; FZDs: Frizzleds; GAS5: Growth arrest-specific 5; GEO: Gene expression omnibus; GHET1: Gastric carcinoma proliferation enhancing transcript 1; GSK-3ß: Glycogen synthase kinase 3ß; HIF-1a: Hypoxia-inducible factor-1alpha; HNF1A-AS1: HNF1A antisense RNA 1; HNRNPL: Heterogeneous nuclear ribonucleoprotein L; HOTTIP: HOXA transcript at the distal tip; ITGB2-AS1: ITGB2 antisense RNA1; LDH: Lactate dehydrogenase; LEF: Lymphoid enhancer factor; LEF1-AS1: Lymphoid enhancer-binding factor 1 antisense RNA 1; LncRNAs: Long noncoding RNAs; LRPs: Lipoprotein receptor-related proteins; LSINCT5: Long stress-induced noncoding transcript 5; MALAT1: Metastasis-associated lung adenocarcinoma transcript 1; MDR1: Multidrug resistance 1; MEG3: Maternally expressed gene 3; MMPs: Matrix metalloproteinases; ncRNAs: Non-coding RNAs; NFAT: Nuclear factor of activated T cells; PCP: Planar cell polarity; P-gp: Glycoprotein; PKC: Protein kinase C; PLC: Phospholipase C; PP2A: Protein phosphatase 2A; qRT-PCR: Quantitative real time polymerase chain reaction; ROC: Receiver operating characteristic; ROR2: Receptor tyrosine kinase-like orphan receptor 2; RYK: Receptor-like tyrosine kinase; sFRP2: Secreted Fzdrelated protein 2; sgRNA: Single-guide RNA; siRNA: Small interfering RNA; Sirt1: Sirtuin 1; SNHG1: Small nucleolar RNA host gene 1; SNHG10: Small nucleolar RNA host gene 10; SUZ12: Suppressor of zeste 12; TCF: T cell factor; TCGA: The Cancer Genome Atlas; TICs: Tumor initiating cells; TMPO-AS1:TMPO antisense RNA 1;TUFT1: Tuftelin1; TUG1: Taurine upregulated gene 1; UCA1: Urothelial carcinoma associated 1; USP47: Ubiquitin-specific peptidase 47; VEGFs: Vascular endothelial growth factor; Wif-1: Wnt inhibitory factor 1; ZEB1: Zinc finger E-box-binding homeobox 1.

\section{Acknowledgements}

This work was supported by the National Natural Science Foundation of China (81902745). All figures were created with Biorender.com.

\section{Authors' contributions}

Writing and figure design: $\mathrm{CT}$ and JYH; Review and editing: JYH, LL, ZYL, $X \mathrm{LR}$, and LW; Conceptualization, review and critical revision: $C T$ and $Z H L$. All authors have read and approved the published version of manuscript.

\section{Funding}

This work was supported by the National Natural Science Foundation of China [81902745].

\section{Availability of Data and materials}

Not applicable.

\section{Declarations}

Ethics approval and consent to participate

Not applicable.

\section{Consent for publication}

Not applicable.

\section{Competing interests}

None declared.

\section{Author details}

${ }^{1}$ Department of Orthopedics, The Second Xiangya Hospital, Central South University, No 139 Middle Renmin Road, Changsha 410011, Hunan, China. ${ }^{2}$ Hunan Key Laboratory of Tumor Models and Individualized Medicine, The Second Xiangya Hospital, Central South University, Changsha 410011, Hunan, China. ${ }^{3}$ Department of Geriatrics, The Second Xiangya Hospital, Central South University, Changsha 410011, Hunan, China.

Received: 7 March 2021 Accepted: 10 June 2021

Published online: 15 June 2021

\section{References}

1. Han J, Shen X. Long noncoding RNAs in osteosarcoma via various signaling pathways. J Clin Lab Anal. 2020;34(6):e23317.

2. Lu KH, Lu EW, Lin CW, Yang JS, Yang SF. New insights into molecular and cellular mechanisms of zoledronate in human osteosarcoma. Pharmacol Ther. 2020;214:107611.

3. Fathizadeh $\mathrm{H}$, Mirzaei $\mathrm{H}$, Asemi Z. Melatonin: an anti-tumor agent for osteosarcoma. Cancer Cell Int. 2019;19:319.

4. Moukengue B, Brown HK, Charrier C, Battaglia S, Baud'huin M, Quillard T, et al. TH1579, MTH1 inhibitor, delays tumour growth and inhibits metastases development in osteosarcoma model. EBioMedicine. 2020;53:102704

5. Gill J, Ahluwalia MK, Geller D, Gorlick R. New targets and approaches in osteosarcoma. Pharmacol Ther. 2013;137(1):89-99.

6. Danieau G, Morice S, Redini F, Verrecchia F, Royer BB. New insights about the Wnt/beta-catenin signaling pathway in primary bone tumors and their microenvironment: a promising target to develop therapeutic strategies? Int J Mol Sci. 2019;20(15):3751.

7. Otoukesh B, Boddouhi B, Moghtadaei M, Kaghazian P, Kaghazian M. Novel molecular insights and new therapeutic strategies in osteosarcoma. Cancer Cell Int. 2018;18:158. 
8. Zhang C, He J, Qi L, Wan L, Wang W, Tu C, et al. Diagnostic and Prognostic Significance of Dysregulated Expression of Circular RNAs in Osteosarcoma. Expert Rev Mol Diagn. 2021;21(2):235-44.

9. Zhang C, Ren X, Liu Z, Tu C. Upregulated expression of LncRNA nicotinamide nucleotide transhydrogenase antisense RNA 1 is correlated with unfavorable clinical outcomes in cancers. BMC Cancer. 2020;20(1):879.

10. Tu C, Ren X, He J, Zhang C, Chen R, Wang W, et al. The value of LncRNA BCAR4 as a prognostic biomarker on clinical outcomes in human cancers. J Cancer. 2019;10(24):5992-6002.

11. Liu B, Zhao H, Zhang L, Shi X. Silencing of long-non-coding RNA ANCR suppresses the migration and invasion of osteosarcoma cells by activating the p38MAPK signalling pathway. BMC Cancer. 2019;19(1):1112.

12. Catana CS, Crisan CA, Opre D, Berindan-Neagoe I. Implications of long non-coding RNAs in age-altered proteostasis. Aging Dis. 2020;11(3):692-704

13. He J, Tu C, Liu Y. Role of IncRNAs in aging and age-related diseases. Aging Med (Milton). 2018;1(2):158-75.

14. Sousa-Franco A, Rebelo K, da Rocha ST, Bernardes de Jesus B. LncRNAs regulating stemness in aging. Aging Cell. 2019;18(1):e12870.

15. Zhao Y, Zhang Y, Zhang L, Dong Y, Ji H, Shen L. The potential markers of circulating microRNAs and long non-coding RNAs in Alzheimer's disease. Aging Dis. 2019;10(6):1293-301.

16. Zhu J, Yu W, Wang Y, Xia K, Huang Y, Xu A, et al. IncRNAs: function and mechanism in cartilage development, degeneration, and regeneration. Stem Cell Res Ther. 2019;10(1):344.

17. Ren X, He J, Qi L, Li S, Zhang C, Duan Z, et al. Prognostic and clinicopathologic significance of long non-coding RNA opa-interacting protein 5-antisense RNA 1 in multiple human cancers. Artif Cells Nanomed Biotechnol. 2020;48(1):353-61.

18. Tu C, Ren X, He J, Li S, Qi L, Duan Z, et al. The predictive value of IncRNA MIR31HG expression on clinical outcomes in patients with solid malignant tumors. Cancer Cell Int. 2020;20:115

19. Zhang ZC, Tang C, Dong Y, Zhang J, Yuan T, Li XL. Targeting LncRNAMALAT1 suppresses the progression of osteosarcoma by altering the expression and localization of beta-catenin. J Cancer. 2018;9(1):71-80.

20. Tu C, He J, Chen R, Li Z. The emerging role of exosomal noncoding RNAs in musculoskeletal diseases. Curr Pharm Des. 2019;25(42):4523-35.

21. Castro-Oropeza R, Melendez-Zajgla J, Maldonado V, Vazquez-Santillan $\mathrm{K}$. The emerging role of IncRNAs in the regulation of cancer stem cells. Cell Oncol (Dordr). 2018:41(6):585-603.

22. Chen S, Shen X. Long noncoding RNAs: functions and mechanisms in colon cancer. Mol Cancer. 2020;19(1):167.

23. Yang G, Shen T, Yi X, Zhang Z, Tang C, Wang L, et al. Crosstalk between long non-coding RNAs and Wnt/beta-catenin signalling in cancer. J Cell Mol Med. 2018:22(4):2062-70.

24. Yao RW, Wang Y, Chen LL. Cellular functions of long noncoding RNAs. Nat Cell Biol. 2019;21(5):542-51.

25. Guh CY, Hsieh YH, Chu HP. Functions and properties of nuclear IncRNAsfrom systematically mapping the interactomes of IncRNAs. J Biomed Sci. 2020;27(1):44.

26. Aillaud $M$, Schulte $L N$. Emerging roles of long noncoding RNAs in the cytoplasmic milieu. Noncoding RNA. 2020;6(4):44.

27. Tu C, Yang K, Wan L, He J, Qi L, Wang W, et al. The crosstalk between IncRNAs and the Hippo signalling pathway in cancer progression. Cell Prolif. 2020;53(9):e12887.

28. McManus MM, Weiss KR, Hughes DP. Understanding the role of Notch in osteosarcoma. Adv Exp Med Biol. 2014;804:67-92.

29. Deng Q, Li P, Che M, Liu J, Biswas S, Ma G, et al. Activation of hedgehog signaling in mesenchymal stem cells induces cartilage and bone tumor formation via Wnt/beta-Catenin. Elife. 2019;8:e50208.

30. Liu J, Kong D, Sun D, Li J. Long non-coding RNA CCAT2 acts as an oncogene in osteosarcoma through regulation of miR-200b/NEGF. Artif Cells Nanomed Biotechnol. 2019;47(1):2994-3003.

31. Subramaniam $D$, Angulo P, Ponnurangam S, Dandawate P, Ramamoorthy $P$, Srinivasan $P$, et al. Suppressing STAT5 signaling affects osteosarcoma growth and stemness. Cell Death Dis. 2020;11(2):149.

32. Angulo P, Kaushik G, Subramaniam D, Dandawate P, Neville K, Chastain $\mathrm{K}$, et al. Natural compounds targeting major cell signaling pathways: a novel paradigm for osteosarcoma therapy. J Hematol Oncol. 2017;10(1):10

33. Zhang Y, Pu Y, Wang J, Li Z, Wang H. Research progress regarding the role of long non-coding RNAs in osteosarcoma. Oncol Lett. 2020;20(3):2606-12.

34. Zarkou V, Galaras A, Giakountis A, Hatzis P. Crosstalk mechanisms between the WNT signaling pathway and long non-coding RNAs. Noncoding RNA Res. 2018;3(2):42-53.

35. Worthmuller J, Ruegg C. The crosstalk between FAK and Wnt signaling pathways in cancer and its therapeutic implication. Int J Mol Sci. 2020;21(23):9107.

36. Nusse R, Varmus HE. Many tumors induced by the mouse mammary tumor virus contain a provirus integrated in the same region of the host genome. Cell. 1982;31(1):99-109.

37. Singla A, Wang J, Yang R, Geller DS, Loeb DM, Hoang BH. Wnt signaling in osteosarcoma. Adv Exp Med Biol. 2020;1258:125-39.

38. Kahn M. Wnt signaling in stem cells and cancer stem cells: a tale of two coactivators. Prog Mol Biol Transl Sci. 2018;153:209-44.

39. van Loon K, Huijbers EJM, Griffioen AW. Secreted frizzled-related protein 2: a key player in noncanonical Wnt signaling and tumor angiogenesis. Cancer Metastasis Rev. 2021;40(1):191-203.

40. Xu X, Zhang $M, X u F$, Jiang $S$. Wnt signaling in breast cancer: biological mechanisms, challenges and opportunities. Mol Cancer. 2020;19(1):165.

41. Castagnoli L, Tagliabue E, Pupa SM. Inhibition of the Wnt signalling pathway: an avenue to control breast cancer aggressiveness. Int J Mol Sci. 2020;21 (23):9069.

42. Flanagan DJ, Vincan E, Phesse TJ. Wnt signaling in cancer: not a binary ON:OFF switch. Cancer Res. 2019;79(23):5901-6.

43. Olsen JJ, Pohl SO, Deshmukh A, Visweswaran M, Ward NC, Arfuso F, et al. The role of Wnt signalling in angiogenesis. Clin Biochem Rev. 2017;38(3):131-42.

44. Sharma M, Pruitt K. Wnt pathway: an integral hub for developmental and oncogenic signaling networks. Int J Mol Sci. 2020;21 (21):8018.

45. Corda G, Sala G, Lattanzio R, lezzi M, Sallese M, Fragassi G, et al. Functional and prognostic significance of the genomic amplification of frizzled 6 (FZD6) in breast cancer. J Pathol. 2017:241(3):350-61.

46. Koushyar S, Powell AG, Vincan E, Phesse TJ. Targeting Wnt signaling for the treatment of gastric cancer. Int J Mol Sci. 2020;21(11):3927.

47. Zhang M, Atkinson RL, Rosen JM. Selective targeting of radiation-resistant tumor-initiating cells. Proc Natl Acad Sci U S A. 2010;107(8):3522-7.

48. Zuccarini M, Giuliani P, Ziberi S, Carluccio M, lorio PD, Caciagli F, et al. The role of Wnt signal in glioblastoma development and progression: a possible new pharmacological target for the therapy of this tumor. Genes (Basel). 2018;9(2):105.

49. Fukuda T, Chen L, Endo T, Tang L, Lu D, Castro JE, et al. Antisera induced by infusions of autologous Ad-CD154-leukemia B cells identify ROR1 as an oncofetal antigen and receptor for Wnt5a. Proc Natl Acad Sci U S A. 2008;105(8):3047-52.

50. Grainger S, Traver D, Willert K. Wnt signaling in hematological malignancies. Prog Mol Biol Transl Sci. 2018;153:321-41.

51. Kawano Y, Kypta R. Secreted antagonists of the Wnt signalling pathway. J Cell Sci. 2003;1 16(Pt 13):2627-34.

52. Dufourcq P, Leroux L, Ezan J, Descamps B, Lamaziere JM, Costet $P$, et al. Regulation of endothelial cell cytoskeletal reorganization by a secreted frizzled-related protein-1 and frizzled 4- and frizzled 7-dependent pathway: role in neovessel formation. Am J Pathol. 2008;172(1):37-49.

53. Zhao S, Kurenbekova L, Gao Y, Roos A, Creighton CJ, Rao P, et al. NKD2, a negative regulator of Wnt signaling, suppresses tumor growth and metastasis in osteosarcoma. Oncogene. 2015;34(39):5069-79.

54. Pederson L, Ruan M, Westendorf JJ, Khosla S, Oursler MJ. Regulation of bone formation by osteoclasts involves Wnt/BMP signaling and the chemokine sphingosine-1-phosphate. Proc Natl Acad Sci U S A. 2008;105(52):20764-9.

55. Wang L, Zhang Q, Chen W, Shan B, Ding Y, Zhang G, et al. B7-H3 is overexpressed in patients suffering osteosarcoma and associated with tumor aggressiveness and metastasis. PLOS ONE. 2013;8(8):e70689.

56. Yin $\mathrm{SJ}$, Wang WJ, Zhang JY. Expression of B7-H3 in cancer tissue during osteosarcoma progression in nude mice. Genet Mol Res. 2015;14(4):14253-61.

57. Galluzzi L, Spranger S, Fuchs E, Lopez-Soto A. WNT signaling in cancer immunosurveillance. Trends Cell Biol. 2019;29(1):44-65. 
58. Westendorf JJ, Kahler RA, Schroeder TM. Wnt signaling in osteoblasts and bone diseases. Gene. 2004;341:19-39.

59. Zhong Z, Zylstra-Diegel CR, Schumacher CA, Baker JJ, Carpenter AC, Rao $S$, et al. Wntless functions in mature osteoblasts to regulate bone mass. Proc Natl Acad Sci U S A. 2012;109(33):E2197-204.

60. Adamopoulos C, Gargalionis AN, Basdra EK, Papavassiliou AG. Deciphering signaling networks in osteosarcoma pathobiology. Exp Biol Med (Maywood). 2016;241(12):1296-305.

61. Ying Y, Tao Q. Epigenetic disruption of the WNT/beta-catenin signaling pathway in human cancers. Epigenetics. 2009:4(5):307-12.

62. McQueen P, Ghaffar S, Guo Y, Rubin EM, Zi X, Hoang BH. The Wnt signaling pathway: implications for therapy in osteosarcoma. Expert Rev Anticancer Ther. 2011;11(8):1223-32.

63. Huang Q, Shi SY, Ji HB, Xing SX. LncRNA BE503655 inhibits osteosarcoma cell proliferation, invasion/migration via Wnt/beta-catenin pathway. 2019. Biosci Rep. https://doi.org/10.1042/BSR20182200.

64. Lu X, Qiao L, Liu Y. Long noncoding RNA LEF1-AS1 binds with HNRNPL to boost the proliferation, migration, and invasion in osteosarcoma by enhancing the mRNA stability of LEF1. J Cell Biochem. 2020:121(10):4064.

65. Ma Y, Ren Y, Han EQ, Li H, Chen D, Jacobs JJ, et al. Inhibition of the Wnt-beta-catenin and Notch signaling pathways sensitizes osteosarcoma cells to chemotherapy. Biochem Biophys Res Commun. 2013:431(2):274-9.

66. Roslan Z, Muhamad M, Selvaratnam L, Ab-Rahim S. The roles of lowdensity lipoprotein receptor-related proteins 5, 6, and 8 in cancer: a review. J Oncol. 2019:2019:4536302.

67. Hoang BH, Kubo T, Healey JH, Sowers R, Mazza B, Yang R, et al. Expression of LDL receptor-related protein 5 (LRP5) as a novel marker for disease progression in high-grade osteosarcoma. Int J Cancer. 2004;109(1):106-11.

68. Guo Y, Zi X, Koontz Z, Kim A, Xie J, Gorlick R, et al. Blocking Wnt/LRP5 signaling by a soluble receptor modulates the epithelial to mesenchymal transition and suppresses met and metalloproteinases in osteosarcoma Saos-2 cells. J Orthop Res. 2007:25(7):964-71.

69. Guo Y, Rubin EM, Xie J, Zi X, Hoang BH. Dominant negative LRP5 decreases tumorigenicity and metastasis of osteosarcoma in an animal model. Clin Orthop Relat Res. 2008:466(9):2039-45.

70. Kim H, Yoo S, Zhou R, Xu A, Bernitz JM, Yuan Y, et al. Oncogenic role of SFRP2 in p53-mutant osteosarcoma development via autocrine and paracrine mechanism. Proc Natl Acad Sci U S A. 2018:115(47):E11128-37.

71. Techavichit P, Gao Y, Kurenbekova L, Shuck R, Donehower LA, Yustein JT. Secreted Frizzled-Related Protein 2 (SFRP2) promotes osteosarcoma invasion and metastatic potential. BMC Cancer. 2016;16(1):869.

72. Basu-Roy U, Basilico C, Mansukhani A. Perspectives on cancer stem cells in osteosarcoma. Cancer Lett. 2013;338(1):158-67.

73. Lin CH, Guo Y, Ghaffar S, McQueen P, Pourmorady J, Christ A, et al. Dkk3 , a secreted wnt antagonist, suppresses tumorigenic potential and pulmonary metastasis in osteosarcoma. Sarcoma. 2013;2013:147541.

74. Sneeggen M, Guadagno NA, Progida C. Intracellular transport in cancer metabolic reprogramming. Front Cell Dev Biol. 2020;8:597608.

75. Yao Q, Chen T. LINC01128 regulates the development of osteosarcoma by sponging miR-299-3p to mediate MMP2 expression and activating Wnt/beta-catenin signalling pathway. J Cell Mol Med. 2020;24(24):14293-305

76. Chen $Y, Y u X, X u Y$, Shen H. Identification of dysregulated IncRNAs profiling and metastasis-associated IncRNAs in colorectal cancer by genome-wide analysis. Cancer Med. 2017:6(10):2321-30.

77. Zhu S, Liu Y, Wang X, Wang J, Xi G. IncRNA SNHG10 promotes the proliferation and invasion of osteosarcoma via Wnt/beta-catenin signaling. Mol Ther Nucleic Acids. 2020;22:957-70.

78. Koren E, Fuchs Y. The ARTS of cell death. J Cell Death. 2019:12:1179066019836967.

79. Brock CK, Wallin ST, Ruiz OE, Samms KM, Mandal A, Sumner EA, et al. Stem cell proliferation is induced by apoptotic bodies from dying cells during epithelial tissue maintenance. Nat Commun. 2019;10(1):1044.

80. Miano V, Ferrero G, Reineri S, Caizzi L, Annaratone L, Ricci L, et al. Luminal long non-coding RNAs regulated by estrogen receptor alpha in a ligand-independent manner show functional roles in breast cancer. Oncotarget. 2016;7(3):3201-16.
81. Xu J, Wu G, Zhao Y, Han Y, Zhang S, Li C, et al. Long noncoding RNA DSCAM-AS1 facilitates colorectal cancer cell proliferation and migration via miR-137/Notch1 axis. J Cancer. 2020;11(22):6623-32.

82. Niknafs YS, Han S, Ma T, Speers C, Zhang C, Wilder-Romans K, et al. The IncRNA landscape of breast cancer reveals a role for DSCAM-AS1 in breast cancer progression. Nat Commun. 2016;7:12791.

83. Ma Y, Bu D, Long J, Chai W, Dong J. LncRNA DSCAM-AS1 acts as a sponge of miR-137 to enhance Tamoxifen resistance in breast cancer. J Cell Physiol. 2019;234(3):2880-94.

84. Zhang S, Ding L, Gao F, Fan H. Long non-coding RNA DSCAM-AS1 upregulates USP47 expression through sponging miR-101-3p to accelerate osteosarcoma progression. Biochem Cell Biol. 2020;98(5):600-11.

85. Lin H, Wu T, Peng L, Su W, Wang Y, Li X, et al. Lnc-MAP6-1:3 knockdown inhibits osteosarcoma progression by modulating Bax/BCl-2 and Wnt/ beta-catenin pathways. Int J Med Sci. 2020;17(15):2248-56.

86. Cui H, Zhao J. LncRNA TMPO-AS1 serves as a ceRNA to promote osteosarcoma tumorigenesis by regulating miR-199a-5p/WNT7B axis. J Cell Biochem. 2020;121(3):2284-93.

87. Yuan G, Quan J, Dong D, Wang Q. Long noncoding RNA CAT104 promotes cell viability, migration, and invasion in gastric carcinoma cells through activation of microrna-381-inhibiting zinc finger e-box-binding homeobox 1 (ZEB1) expression. Oncol Res. 2018;26(7):1037-46.

88. Zhang C, Song G, Song G, Li R, Gao M, Zhang H. CAT104 silence behaves as a tumor suppressor in human leukemia cells by down regulating miR-182 expression. Int J Clin Exp Pathol. 2017;10(12):11393-404.

89. Xia B, Wang L, Feng L, Tian B, Tan Y, Du B. Knockdown of long noncoding RNA CAT104 inhibits the proliferation, migration, and invasion of human osteosarcoma cells by regulating MicroRNA-381. Oncol Res. 2018;27(1):89-98.

90. Yu X, Hu L, Li S, Shen J, Wang D, Xu R, et al. Long non-coding RNA Taurine upregulated gene 1 promotes osteosarcoma cell metastasis by mediating HIF-1alpha via miR-143-5p. Cell Death Dis. 2019;10(4):280.

91. Ghafouri-Fard S, Taheri M. Maternally expressed gene 3 (MEG3): a tumor suppressor long non coding RNA. Biomed Pharmacother. 2019;118:109129.

92. Chak WP, Lung RW, Tong JH, Chan SY, Lun SW, Tsao SW, et al. Downregulation of long non-coding RNA MEG3 in nasopharyngeal carcinoma. Mol Carcinog. 2017;56(3):1041-54.

93. Zhu M, Wang F, Mi H, Li L, Wang J, Han M, et al. Long noncoding RNA MEG3 suppresses cell proliferation, migration and invasion, induces apoptosis and paclitaxel-resistance via miR-4513/PBLD axis in breast cancer cells. Cell Cycle. 2020;19(23):3277-88.

94. Zheng $Y$, Wang $M$, Wang $S$, Xu P, Deng $Y$, Lin $S$, et al. LncRNA MEG3 rs3087918 was associated with a decreased breast cancer risk in a Chinese population: a case-control study. BMC Cancer. 2020;20(1):659.

95. Liu Y, Xu Y, Ding L, Yu L, Zhang B, Wei D. LncRNA MEG3 suppressed the progression of ovarian cancer via sponging miR-30e-3p and regulating LAMA4 expression. Cancer Cell Int. 2020;20:181.

96. Li L, Pei S, Sun N. MEG3 targets miR-184 and Wnt/beta-catenin and modulates properties of osteosarcoma. Front Biosci (Landmark Ed). 2020;25:1901-12.

97. Zhu G, Liu X, Su Y, Kong F, Hong X, Lin Z. Knockdown of urothelial carcinoma-associated 1 suppressed cell growth and migration through regulating miR-301a and CXCR4 in osteosarcoma MHCC97 cells. Oncol Res. 2018;27(1):55-64.

98. Gong C, Sun K, Xiong HH, Sneh T, Zhang J, Zhou X, et al. Expression of CXCR4 and MMP-2 is associated with poor prognosis in patients with osteosarcoma. Histol Histopathol. 2020;35(8):863-70.

99. Xi Y, Qi Z, Ma J, Chen Y. PTEN loss activates a functional AKT/CXCR4 signaling axis to potentiate tumor growth and lung metastasis in human osteosarcoma cells. Clin Exp Metastasis. 2020;37(1):173-85.

100. Yin J, Chen D, Luo K, Lu M, Gu Y, Zeng S, et al. Cip2a/miR-301a feedback loop promotes cell proliferation and invasion of triple-negative breast cancer. J Cancer. 2019;10(24):5964-74.

101. Ni Z, Shang XF, Wang YF, Sun YJ, Fu DJ. Upregulated microRNA-301a in osteosarcoma promotes tumor progression by targeting CDC14A. Genet Mol Res. 2016. https://doi.org/10.4238/gmr.15027807.

102. Zhang Y, Duan G, Feng S. MicroRNA-301a modulates doxorubicin resistance in osteosarcoma cells by targeting AMP-activated protein kinase alpha 1. Biochem Biophys Res Commun. 2015;459(3):367-73.

103. Tian Z, Yang G, Jiang P, Zhang L, Wang J, Sun S. Long non-coding RNA Sox 4 promotes proliferation and migration by activating 
Wnt/beta-catenin signaling pathway in osteosarcoma. Pharmazie 2017;72(9):537-42.

104. Jia D, Niu Y, Li D, Liu Z. IncRNA C2dat1 promotes cell proliferation, migration, and invasion by targeting miR-34a-5p in osteosarcoma cells. Oncol Res. 2018;26(5):753-64.

105. Sun X, Wang M, Wang M, Yao L, Li X, Dong H, et al. Exploring the metabolic vulnerabilities of epithelial-mesenchymal transition in breast cancer. Front Cell Dev Biol. 2020;8:655.

106. Chen X, Zhao W, Fan W. Long noncoding RNA GHET1 promotes osteosarcoma development and progression via Wnt/betacatenin signaling pathway. Oncol Rep. 2020;44(1):349-59.

107. Ding Q, Mo F, Cai X, Zhang W, Wang J, Yang S, et al. LncRNA CRNDE is activated by SP1 and promotes osteosarcoma proliferation, invasion, and epithelial-mesenchymal transition via Wnt/beta-catenin signaling pathway. J Cell Biochem. 2020;121(5-6):3358-71.

108. Cao J, Han X, Qi X, Jin X, Li X. TUG1 promotes osteosarcoma tumorigenesis by upregulating EZH2 expression via miR-144-3p. Int J Oncol. 2017:51(4):1115-23.

109. Yang G, Zhang C, Wang N, Chen J. miR-425-5p decreases LncRNA MALAT1 and TUG1 expressions and suppresses tumorigenesis in osteosarcoma via Wnt/beta-catenin signaling pathway. Int J Biochem Cell Biol. 2019;111:42-51.

110. Andrade-Tomaz M, de Souza I, Rocha CRR, Gomes LR. The role of chaperone-mediated autophagy in cell cycle control and its implications in cancer. Cells. 2020;9(9):2140.

111. Ameratunga M, Kipps E, Okines AFC, Lopez JS. To cycle or fight-CDK4/6 inhibitors at the crossroads of anticancer immunity. Clin Cancer Res. 2019;25(1):21-8.

112. Wang Y, Dou L, Qin Y, Yang H, Yan P. OIP5-AS1 contributes to tumorigenesis in hepatocellular carcinoma by miR-300/YY1-activated WNT pathway. Cancer Cell Int. 2020;20:440.

113. Zhao R, Zhang $X$, Zhang $Y$, Zhang $Y$, Yang $Y$, Sun $Y$, et al. HOTTIP predicts poor survival in gastric cancer patients and contributes to cisplatin resistance by sponging miR-216a-5p. Front Cell Dev Biol. 2020;8:348.

114. Zhao R, Zhang $Y$, Zhang $X$, Yang $Y$, Zheng $X$, Li X, et al. Exosomal long noncoding RNA HOTTIP as potential novel diagnostic and prognostic biomarker test for gastric cancer. Mol Cancer. 2018;17(1):68.

115. Zhang GJ, Song W, Song Y. Overexpression of HOTTIP promotes proliferation and drug resistance of lung adenocarcinoma by regulating AKT signaling pathway. Eur Rev Med Pharmacol Sci. 2017;21 (24):5683-90.

116. Sun $Q$, Zhang SY, Zhao JF, Han XG, Wang HB, Sun ML. HIF-1 alpha or HOTTIP/CTCF promotes head and neck squamous cell carcinoma progression and drug resistance by targeting HOXA9. Mol Ther Nucleic Acids. 2020;20:164-75.

117. Xie W, Chu M, Song G, Zuo Z, Han Z, Chen C, et al. Emerging roles of long noncoding RNAs in chemoresistance of pancreatic cancer. Semin Cancer Biol. 2020. https://doi.org/10.1016/j.semcancer.2020.11.004.

118. Wong CH, Li CH, He Q, Chan SL, Tong JH, To KF, et al. Ectopic HOTTIP expression induces noncanonical transactivation pathways to promote growth and invasiveness in pancreatic ductal adenocarcinoma. Cancer Lett. 2020;477:1-9.

119. Li Z, Zhao L, Wang Q. Overexpression of long non-coding RNA HOTTIP increases chemoresistance of osteosarcoma cell by activating the Wnt/ beta-catenin pathway. Am J Transl Res. 2016;8(5):2385-93.

120. Shen C, Yang C, Xia B, You M. Long non-coding RNAs: emerging regulators for chemo/immunotherapy resistance in cancer stem cells. Cancer Lett. 2020:500:244-52.

121. Chen Z, Gao Y, Yao L, Liu Y, Huang L, et al. LncFZD6 initiates Wnt/ beta-catenin and liver TIC self-renewal through BRG1-mediated FZD6 transcriptional activation. Oncogene. 2018;37(23):3098-112.

122. Tian J, Gu Y, Li Y, Liu T. CD271 antibody-functionalized HGNs for targeted photothermal therapy of osteosarcoma stem cells. Nanotechnology. 2020;31(30):305707.

123. Zhang RM, Tang T, Yu HM, Yao XD. LncRNA DLX6-AS1/miR-129-5p/ DLK1 axis aggravates stemness of osteosarcoma through Wnt signaling. Biochem Biophys Res Commun. 2018;507(1-4):260-6.

124. Izadpanah S, Shabani P, Aghebati-Maleki A, Baghbanzadeh A, Fotouhi A, Bisadi A, et al. Prospects for the involvement of cancer stem cells in the pathogenesis of osteosarcoma. J Cell Physiol. 2020;235(5):4167-82.
125. Li F, XuY, Xu X, Ge S, Zhang F, Zhang H, et al. LncRNA HotairM1 depletion promotes self-renewal of cancer stem cells through HOXA1-nanog regulation loop. Mol Ther Nucleic Acids. 2020;22:456-70.

126. Zhang S, Wan H, Zhang X. LncRNA LHFPL3-AS1 contributes to tumorigenesis of melanoma stem cells via the miR-181a-5p/BCL2 pathway. Cell Death Dis. 2020;11(11):950.

127. Zhang N, Meng X, Mei L, Zhao C, Chen W. LncRNA DLX6-AS1 promotes tumor proliferation and metastasis in osteosarcoma through modulating miR-641/HOXA9 signaling pathway. J Cell Biochem. 2019;120(7):11478-89.

128. Hu C, Liu K, Wang B, Xu W, Ling Y, Yuan C. DLX6-AS1: an indispensable cancer-related long non-coding RNA. Curr Pharm Des. 2020:27(9):1211-8.

129. Wang SY, Hu HZ, Qing XC, Zhang ZC, Shao ZW. Recent advances of drug delivery nanocarriers in osteosarcoma treatment. J Cancer. 2020;11(1):69-82.

130. Luo X, Wei J, Yang FL, Pang XX, Shi F, Wei YX, et al. Exosomal IncRNA HNF1A-AS1 affects cisplatin resistance in cervical cancer cells through regulating microRNA-34b/TUFT1 axis. Cancer Cell Int. 2019;19:323.

131. Tian F, Dahmani FZ, Qiao J, Ni J, Xiong H, Liu T, et al. A targeted nanoplatform co-delivering chemotherapeutic and antiangiogenic drugs as a tool to reverse multidrug resistance in breast cancer. Acta Biomater. 2018;75:398-412.

132. Chen $Z$, Pan $T$, Jiang $D$, Jin $L$, Geng $Y$, Feng $X$, et al. The IncRNA-GAS5/ miR-221-3p/DKK2 axis modulates ABCB1-mediated adriamycin resistance of breast cancer via the Wnt/beta-catenin signaling pathway. Mol Ther Nucleic Acids. 2020;19:1434-48.

133. Ruiz MC, Resasco A, Di Virgilio AL, Ayala M, Cavaco I, Cabrera S, et al. In vitro and in vivo anticancer effects of two quinoline-platinum(II) complexes on human osteosarcoma models. Cancer Chemother Pharmacol. 2019:83(4):681-92.

134. Benjamin RS. Adjuvant and neoadjuvant chemotherapy for osteosarcoma: a historical perspective. Adv Exp Med Biol. 2020;1257:1-10.

135. Liu W, Dong X, Mai M, Seelan RS, Taniguchi K, Krishnadath KK, et al. Mutations in AXIN2 cause colorectal cancer with defective mismatch repair by activating beta-catenin/TCF signalling. Nat Genet. 2000;26(2):146-7.

136. Satoh S, Daigo Y, Furukawa Y, Kato T, Miwa N, Nishiwaki T, et al. AXIN1 mutations in hepatocellular carcinomas, and growth suppression in cancer cells by virus-mediated transfer of AXIN1. Nat Genet. 2000;24(3):245-50.

137. Kinzler KW, Nilbert MC, Su LK, Vogelstein B, Bryan TM, Levy DB, et al. Identification of FAP locus genes from chromosome 5q21. Science. 1991;253(5020):661-5.

138. Koo BK, Spit M, Jordens I, LoW TY, Stange DE, van de Wetering M, et al. Tumour suppressor RNF43 is a stem-cell E3 ligase that induces endocytosis of Wnt receptors. Nature. 2012:488(7413):665-9.

139. Nanki K, Toshimitsu K, Takano A, Fujii M, Shimokawa M, Ohta Y, et al. Divergent routes toward Wnt and R-spondin niche independency during human gastric carcinogenesis. Cell. 2018;174(4):856-69.

140. Giannakis M, Hodis E, Jasmine MuX, Yamauchi M, Rosenbluh J, Cibulskis $\mathrm{K}$, et al. RNF43 is frequently mutated in colorectal and endometrial cancers. Nat Genet. 2014:46(12):1264-6.

141. Zhao X, Su L, He X, Zhao B, Miao J. Long noncoding RNA CA7-4 promotes autophagy and apoptosis via sponging MIR877-3P and MIR5680 in high glucose-induced vascular endothelial cells. Autophagy. 2020;16(1):70-85.

142. Ren S, Wang F, Shen J, Sun Y, Xu W, Lu J, et al. Long non-coding RNA metastasis associated in lung adenocarcinoma transcript 1 derived miniRNA as a novel plasma-based biomarker for diagnosing prostate cancer. Eur J Cancer. 2013;49(13):2949-59.

143. Ratti M, Lampis A, Ghidini M, Salati M, Mirchev MB, Valeri N, et al. MicroRNAs (miRNAs) and long non-coding RNAs (IncRNAs) as new tools for cancer therapy: first steps from bench to bedside. Target Oncol. 2020;15(3):261-78.

144. Chandra Gupta S, Nandan TY. Potential of long non-coding RNAs in cancer patients: from biomarkers to therapeutic targets. Int J Cancer. 2017;140(9):1955-67. 
145. Jiang S, Kong P, Liu X, Yuan C, Peng K, Liang Y. LncRNA FLVCR1-AS1 accelerates osteosarcoma cells to proliferate, migrate and invade via activating wnt/beta-catenin pathway. J BUON. 2020;25(4):2078-85.

146. Jiang Z, Jiang C, Fang J. Up-regulated Inc-SNHG1 contributes to osteosarcoma progression through sequestration of miR-577 and activation of WNT2B/Wnt/beta-catenin pathway. Biochem Biophys Res Commun. 2018;495(1):238-45.

147. Ding W, Wu D, Ji F, Zhang H. Inhibition of long non-coding RNA-AWPPH decreases osteosarcoma cell proliferation, migration and invasion. Oncol Lett. 2019;18(5):5055-62.

148. Li C, Wang F, Wei B, Wang L, Kong D. LncRNA AWPPH promotes osteosarcoma progression via activation of Wnt/beta-catenin pathway through modulating miR-93-3p/FZD7 axis. Biochem Biophys Res Commun. 2019;514(3):1017-22.

149. Zhao H, Hou W, Tao J, Zhao Y, Wan G, Ma C, et al. Upregulation of IncRNA HNF1A-AS1 promotes cell proliferation and metastasis in osteosarcoma through activation of the Wnt/beta-catenin signaling pathway. Am J Transl Res. 2016;8(8):3503-12.

150. Cai L, LV J, Zhang Y, Li J, Wang Y, Yang H. The IncRNA HNF1A-AS1 is a negative prognostic factor and promotes tumorigenesis in osteosarcoma. J Cell Mol Med. 2017;21 (11):2654-62.

151. He W, Lu M, Xiao D. LSINCT5 predicts unfavorable prognosis and exerts oncogenic function in osteosarcoma. Biosci Rep. 2019;39(5):BSR20190612:

152. Kong D, Li C, Yang Q, Wei B, Wang L, Peng C. Long noncoding RNA LSINCT5 acts as an oncogene via increasing EZH2-induced inhibition of APC expression in osteosarcoma. Biochem Biophys Res Commun. 2018;507(1-4):193-7.

153. Dai J, Xu $\sqcup$, Han GD, Jiang HT, Sun HL, Zhu GT, et al. Down-regulation of long non-coding RNA ITGB2-AS1 inhibits osteosarcoma proliferation and metastasis by repressing Wnt/beta-catenin signalling and predicts favourable prognosis. Artif Cells Nanomed Biotechnol. 2018:46(sup3):S783-90.

154. Zhao BM, Cheng FH, Cai L. Long noncoding RNA AFAP1-AS1 promoted osteosarcoma proliferation and invasion via upregulating BDNF. Eur Rev Med Pharmacol Sci. 2019;23(7):2744-9.

155. Fei $D$, Zhang $X$, Lu Y, Tan L, Xu M, Zhang Y. Long noncoding RNA AFAP1AS1 promotes osteosarcoma progression by regulating miR-497/IGF1R axis. Am J Transl Res. 2020;12(5):2155-68.

156. Shi D, Wu F, Mu S, Hu B, Zhong B, Gao F, et al. LncRNA AFAP1-AS1 promotes tumorigenesis and epithelial-mesenchymal transition of osteosarcoma through RhoC/ROCK1/p38MAPK/Twist1 signaling pathway. J Exp Clin Cancer Res. 2019;38(1):375.

157. Li R, Liu S, Li Y, Tang Q, Xie Y, Zhai R. Long noncoding RNA AFAP1AS1 enhances cell proliferation and invasion in osteosarcoma through regulating miR46955p/TCF4betacatenin signaling. Mol Med Rep. 2018;18(2):1616-22

158. Fan $Q$, Yang L, Zhang $X$, Peng $X$, Wei S, Su D, et al. The emerging role of exosome-derived non-coding RNAs in cancer biology. Cancer Lett. 2018:414:107-15.

159. Zhang H, Wang J, Ren T, Huang Y, Yu Y, Chen C, et al. LncRNA CASC15 is upregulated in osteosarcoma plasma exosomes and CASC15 knockdown inhibits osteosarcoma progression by regulating miR-338-3p/ RAB14 axis. Onco Targets Ther. 2020;13:12055-66.

160. Zhang J, Liu SC, Luo XH, Tao GX, Guan M, Yuan H, et al. Exosomal long noncoding RNAs are differentially expressed in the cervicovaginal lavage samples of cervical cancer patients. J Clin Lab Anal. 2016;30(6):1116-21.

161. Lei L, Mou Q. Exosomal taurine up-regulated 1 promotes angiogenesis and endothelial cell proliferation in cervical cancer. Cancer Biol Ther 2020;21(8):717-25.

162. Chen X, Liu Y, Zhang Q, Liu B, Cheng Y, Zhang Y, et al. Exosomal long non-coding RNA HOTTIP increases resistance of colorectal cancer cells to mitomycin via impairing MiR-214-mediated degradation of KPNA3. Front Cell Dev Biol. 2020;8:582723.

163. Huang H, Du J, Jin B, Pang L, Duan N, Huang C, et al. Combination of urine exosomal mRNAs and IncRNAs as novel diagnostic biomarkers for bladder cancer. Front Oncol. 2021:11:667212.

164. Sun J, Jia H, Bao X, Wu Y, Zhu T, Li R, et al. Tumor exosome promotes Th17 cell differentiation by transmitting the InCRNA CRNDE-h in colorectal cancer. Cell Death Dis. 2021:12(1):123.
165. Zhu Z, Wang H, Pang Y, Hu H, Zhang H, Wang W. Exosomal long noncoding RNA UCA1 functions as growth inhibitor in esophageal cancer. Aging (Albany NY). 2020;12(20):20523-39.

166. Sato F. Significance of noncoding Rna in breast cancer. Nihon Geka Gakkai Zasshi. 2015;116(6):370-3.

167. Han J, Gao L, Wang J, Wang J. Application and development of aptamer in cancer: from clinical diagnosis to cancer therapy. J Cancer. 2020;11(23):6902-15.

168. Lucere KM, O'Malley MMR, Diermeier SD. Functional screening techniques to identify long non-coding RNAs as therapeutic targets in cancer. Cancers (Basel). 2020;12(12):3695.

169. Monia BP, Lesnik EA, Gonzalez C, Lima WF, McGee D, Guinosso CJ, et al. Evaluation of 2'-modified oligonucleotides containing 2'-deoxy gaps as antisense inhibitors of gene expression. J Biol Chem. 1993;268(19):14514-22.

170. Gong N, Teng X, Li J, Liang XJ. Antisense oligonucleotide-conjugated nanostructure-targeting IncRNA MALAT1 inhibits cancer metastasis. ACS Appl Mater Interfaces. 2019;11(1):37-42.

171. Jonchere V, Bennett D. Validating RNAi phenotypes in Drosophila using a synthetic RNAi-resistant transgene. PLoS ONE. 2013;8(8):e70489.

172. Burel SA, Hart CE, Cauntay P, Hsiao J, Machemer T, Katz M, et al. Hepatotoxicity of high affinity gapmer antisense oligonucleotides is mediated by $\mathrm{RNase} \mathrm{H} 1$ dependent promiscuous reduction of very long pre-mRNA transcripts. Nucleic Acids Res. 2016:44(5):2093-109.

173. Jackson AL, Linsley PS. Recognizing and avoiding siRNA off-target effects for target identification and therapeutic application. Nat Rev Drug Discov. 2010;9(1):57-67.

174. Zhen S, Takahashi Y, Narita S, Yang YC, Li X. Targeted delivery of CRISPR/ Cas9 to prostate cancer by modified gRNA using a flexible aptamercationic liposome. Oncotarget. 2017;8(6):9375-87.

175. Xu D, Cai Y, Tang L, Han X, Gao F, Cao H, et al. Kapranov P: A CRISPR/ Cas13-based approach demonstrates biological relevance of vlinc class of long non-coding RNAs in anticancer drug response. Sci Rep. 2020;10(1):1794.

176. Lin CH, Ji T, Chen CF, Hoang BH. Wnt signaling in osteosarcoma. Adv Exp Med Biol. 2014;804:33-45.

177. Zhang W, He L, Liu Z, Ren X, Qi L, Wan L, et al. Multifaceted functions and novel insight into the regulatory role of RNA N(6)-methyladenosine modification in musculoskeletal disorders. Front Cell Dev Biol. 2020;8:870

178. Qi L, Wan L, Ren X, Zhang W, Tu C, Li Z. The role of chemotherapy in extraskeletal osteosarcoma: a propensity score analysis of the surveillance epidemiology and end results (SEER) database. Med Sci Monit. 2020;26:e925107.

179. Qi L, Ren X, Liu Z, Li S, Zhang W, Chen R, et al. Predictors and survival of patients with osteosarcoma after limb salvage versus amputation: a population-based analysis with propensity score matching. World J Surg. 2020;44(7):2201-10.

180. Javed Z, Khan K, Sadia H, Raza S, Salehi B, Sharifi-Rad J, et al. LncRNA \& Wnt signaling in colorectal cancer. Cancer Cell Int. 2020;20:326.

181. He L, Zhou H, Zeng Z, Yao H, Jiang W, Qu H. Wnt/beta-catenin signaling cascade: a promising target for glioma therapy. J Cell Physiol. 2019;234(3):2217-28.

182. Pridgeon MG, Grohar PJ, Steensma MR, Williams BO. Wht signaling in ewing sarcoma, osteosarcoma, and malignant peripheral nerve sheath tumors. Curr Osteoporos Rep. 2017;15(4):239-46.

183. Karimzadeh MR, Seyedtaghia MR, Soudyab M, Nezamnia M, Kidde J, Sahebkar A. Exosomal long noncoding RNAs: insights into emerging diagnostic and therapeutic applications in lung cancer. J Oncol. 2020:2020:7630197.

184. Li L, Zhang X, Liu N, Chen X, Peng C. LINC00473: a novel oncogenic long noncoding RNA in human cancers. J Cell Physiol. 2020;236(6):4174-83.

185. Bao J, Zeng J, Song C, Yu H, Shi Q, Mai W, et al. A retrospective clinicopathological study of osteosarcoma patients with metachronous metastatic relapse. J Cancer. 2019;10(13):2982-90.

186. Zhong J, Hu Y, Si L, Geng J, Xing Y, Jiao Q, et al. Clarifying prognostic factors of small cell osteosarcoma: a pooled analysis of 20 cases and the literature. J Bone Oncol. 2020;24:100305. 
187. Wang Y, Kong D. Knockdown of IncRNA MEG3 inhibits viability, migration, and invasion and promotes apoptosis by sponging miR-127 in osteosarcoma cell. J Cell Biochem. 2018;119(1):669-79.

188. Su Y, Zhou Y, Sun YJ, Wang YL, Yin JY, Huang YJ, et al. Macrophagederived CCL18 promotes osteosarcoma proliferation and migration by upregulating the expression of UCA1. J Mol Med (Berl). 2019:97(1):49-61.

\section{Publisher's Note}

Springer Nature remains neutral with regard to jurisdictional claims in published maps and institutional affiliations.
Ready to submit your research? Choose BMC and benefit from:

- fast, convenient online submission

- thorough peer review by experienced researchers in your field

- rapid publication on acceptance

- support for research data, including large and complex data types

- gold Open Access which fosters wider collaboration and increased citations

- maximum visibility for your research: over $100 \mathrm{M}$ website views per year

At BMC, research is always in progress.

Learn more biomedcentral.com/submissions 